Rowan University

Rowan Digital Works

School of Osteopathic Medicine Faculty

Scholarship

School of Osteopathic Medicine

$1-12-2011$

\title{
Alterations in AMPA Receptor Subunits and Tarps in the Rat Nucleus Accumbens Related to the Formation of Ca2+-Permeable AMPA Receptors During the Incubation of Cocaine Craving
}

\author{
Carrie Ferrario \\ Rosalind Franklin University of Medicine and Science \\ Jessica Loweth \\ Rowan University School of Osteopathic Medicine \\ Mike Milovanovic \\ Rosalind Franklin University of Medicine and Science \\ Kerstin Ford \\ Rosalind Franklin University of Medicine and Science \\ Gregorio Galiñanes

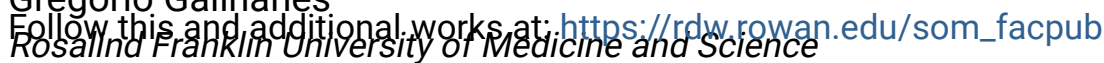 \\ Part of the Behavior and Behavior Mechanisms Commons, Biochemistry Commons, Biology \\ Commons, Cell Biology Commons, Chemicals and Drugs Commons, Neuroscience and Neurobiology \\ See next page for additional authors \\ Commons, Pharmacology Commons, Substance Abuse and Addiction Commons, and the Toxicology \\ Commons
}

\section{Recommended Citation}

Ferrario CR, Loweth JA, Milovanovic M, Ford KA, Galiñanes GL, Heng LJ, Tseng KY, Wolf ME. Alterations in AMPA receptor subunits and TARPs in the rat nucleus accumbens related to the formation of $\mathrm{Ca}^{2+}$ permeable AMPA receptors during the incubation of cocaine craving. Neuropharmacology. 2011 Dec;61(7):1141-51. Epub 2011 Jan 27. doi: 10.1016/j.neuropharm.2011.01.021. PMID: 21276808. PMCID: PMC3094740.

This Article is brought to you for free and open access by the School of Osteopathic Medicine at Rowan Digital Works. It has been accepted for inclusion in School of Osteopathic Medicine Faculty Scholarship by an authorized administrator of Rowan Digital Works. 


\section{Authors}

Carrie Ferrario, Jessica Loweth, Mike Milovanovic, Kerstin Ford, Gregorio Galiñanes, Li Heng, Kuei Tseng, and Marina Wolf

This article is available at Rowan Digital Works: https://rdw.rowan.edu/som_facpub/32 


\title{
Alterations in AMPA receptor subunits and TARPs in the rat nucleus accumbens related to the formation of $\mathrm{Ca}^{2+-}$ permeable AMPA receptors during the incubation of cocaine craving
}

\author{
Carrie R. Ferrario ${ }^{\mathrm{a}, 1}$, Jessica A. Loweth ${ }^{\mathrm{a}}$, Mike Milovanovic ${ }^{\mathrm{a}}$, Kerstin A. Ford ${ }^{\mathrm{a}}$, Gregorio L. \\ Galiñanes $^{\mathrm{b}, 2}$, Li-Jun Heng ${ }^{\mathrm{b}}$, Kuei Y. Tseng ${ }^{\mathrm{b}}$, and Marina E. Wolf ${ }^{\mathrm{a}}$ \\ aDepartment of Neuroscience, Rosalind Franklin University of Medicine and Science, 3333 Green \\ Bay Road, North Chicago, II 60064-3095 \\ bDepartment of Cellular and Molecular Pharmacology, Rosalind Franklin University of Medicine \\ and Science, 3333 Green Bay Road, North Chicago, II 60064-3095
}

\section{Abstract}

Cue-induced cocaine seeking intensifies or incubates after withdrawal from extended access cocaine self-administration, a phenomenon termed incubation of cocaine craving. The expression of incubated craving is mediated by $\mathrm{Ca}^{2+}$-permeable AMPA receptors (CP-AMPARs) in the nucleus accumbens (NAc). Thus, CP-AMPARs are a potential target for therapeutic intervention, making it important to understand mechanisms that govern their accumulation. Here we used subcellular fractionation and biotinylation of NAc tissue to examine the abundance and distribution of AMPAR subunits, and GluA1 phosphorylation, in the incubation model. We also studied two transmembrane AMPA receptor regulatory proteins (TARPs), $\gamma 2$ and $\gamma 4$. Our results, together with earlier findings, suggest that some of the new CP-AMPARs are synaptic. These are probably associated with $\gamma 2$, but they are loosely tethered to the PSD. Levels of GluA1 phosphorylated at serine 845 (pS845 GluA1) were significantly increased in biotinylated tissue and in an extrasynaptic membrane-enriched fraction. These results suggest that increased synaptic levels of CP-AMPARs may result in part from an increase in pS845 GluA1 in extrasynaptic membranes, given that S845 phosphorylation primes GluA1-containing AMPARs for synaptic insertion and extrasynaptic AMPARs supply the synapse. Some of the new extrasynaptic CPAMPARs are likely associated with $\gamma 4$, rather than $\gamma 2$. The maintenance of CP-AMPARs in NAc synapses during withdrawal is accompanied by activation of CaMKII and ERK2 but not CaMKI. Overall, AMPAR plasticity in the incubation model shares some features with better described forms of synaptic plasticity, although the timing of the phenomenon and the persistence of related neuroadaptations is significantly different.

\section{() 2011 Elsevier Ltd. All rights reserved.}

Corresponding author: Marina E. Wolf, Department of Neuroscience, Rosalind Franklin University of Medicine and Science, 3333 Green Bay Road, North Chicago, Il 60064-3095. Tel: (847) 578-8659 Fax: (847) 578-8515, marina.wolf@ rosalindfranklin.edu. ${ }^{1}$ Present address: Pharmacology Department, The University of Michigan, 1000 Wall Street, Ann Arbor, MI, 48105, ferrario@umich.edu

2Present address: Laboratorio de Fisiología de Circuitos Neuronales, Departamento de Fisiología y Biofísica, Facultad de Medicina, Universidad de Buenos Aires, Ciudad de Buenos Aires C1121ABG, Argentina. neurofis@fmed.uba.ar

Publisher's Disclaimer: This is a PDF file of an unedited manuscript that has been accepted for publication. As a service to our customers we are providing this early version of the manuscript. The manuscript will undergo copyediting, typesetting, and review of the resulting proof before it is published in its final citable form. Please note that during the production process errors may be discovered which could affect the content, and all legal disclaimers that apply to the journal pertain.

Disclosure

M.E.W. has no biomedical financial interests but has a patent on A Possible Therapy For Cue-Induced Cocaine Craving Leading to Relapse in Abstinent Cocaine Abusers Based on Blockade of GluR2-lacking AMPA Receptors in the Nucleus Accumbens. The other authors report no biomedical financial interests or potential conflicts of interest. 


\section{Introduction}

Relapse to cocaine use, even after a long period of abstinence, is a critical problem in treating addiction. Relapse is often triggered by craving elicited by cues or contexts previously associated with cocaine (O'Brien et al., 1992). A number of different models exist for studying cue-induced cocaine craving in rats (e.g., Crombag et al., 2008). We are particularly interested in the incubation model. Incubation refers to the progressive intensification of cue-induced cocaine-seeking that occurs after withdrawal from extended access cocaine self-administration. Enhanced drug-seeking in this rat model persists $>3$ months after the last cocaine exposure (Lu et al., 2004). The incubation model is particularly relevant to human cocaine users who undergo prolonged abstinence due to incarceration or hospitalization, and then, once released, encounter previously drug-paired cues that can trigger relapse (Reichel and Bevins, 2009).

Our studies focus on the role of AMPA-type glutamate receptors (AMPARs) in the incubation of cocaine craving. AMPARs are tetramers composed of GluA1-4 subunits (Shepherd and Huganir, 2007). They are associated with auxiliary subunits, including a family of transmembrane AMPA receptor regulatory proteins (TARPs) that regulate AMPAR trafficking, channel properties, and glutamate affinity (Kato et al., 2010). Medium spiny neurons, the output neurons of the nucleus accumbens (NAc), are excited primarily by AMPARs. This is required for drug seeking in many rat models of cocaine addiction, suggesting AMPAR transmission in the NAc as a key control point for craving and relapse (Kalivas, 2009; Wolf and Ferrario, 2010). Therefore, it is important to compare AMPAR transmission in the NAc of drug-naïve rats and rats that have undergone incubation ("incubated rats").

While most AMPARs in the brain contain the GluA2 subunit, there has been considerable recent interest in AMPARs that lack this subunit; these receptors are $\mathrm{Ca}^{2+}$-permeable $(\mathrm{CP}$ AMPARs) and have higher conductance than GluA2-containing, $\mathrm{Ca}^{2+}$-impermeable AMPARs (CI-AMPARs; Cull-Candy et al., 2006; Isaac et al., 2007; Liu and Zukin, 2007). Our recent studies have shown that CP-AMPARs are expressed at very low levels in NAc synapses of adult drug-naïve rats (Conrad et al., 2008; Reimers et al., 2010), but accumulate in association with the incubation of cue-induced cocaine craving and mediate its expression in rats tested on withdrawal day (WD) 45 (Conrad et al., 2008). The presence of CPAMPARs in NAc synapses of "incubated rats" was demonstrated using electrophysiological techniques, a bis(sulfosuccinimidyl)suberate $\left(\mathrm{BS}^{3}\right)$ protein crosslinking assay showing increased cell surface levels of GluA1 but not GluA2, and co-immunoprecipitation experiments showing an increase in levels of GluA1 not physically associated with other AMPAR subunits (Conrad et al., 2008). Although we first demonstrated CP-AMPARs in the NAc core of "incubated rats", we recently showed that they are also present in the rat NAc shell on WD35-49 (McCutcheon et al., 2010). CP-AMPARs have also been detected in the mouse NAc shell after 35 days of withdrawal from extended access cocaine selfadministration (Mameli et al., 2009).

The goal of the present study was to learn more about the subcellular distribution of CPAMPARs in the NAc of "incubated rats" and to understand how these receptors gain access to NAc synapses and accumulate there during withdrawal. To this end, we used subcellular fractionation and biotinylation to examine the abundance and subcellular distribution of AMPAR subunits, as well as GluA1 phosphorylated at serine 845 (pS845 GluA1), in NAc tissue obtained from control rats or "incubated rats" on WD30-45. We also studied two TARPs, $\gamma 2$ and $\gamma 4$, that we have previously shown are expressed in the adult rat NAc (Ferrario et al., in press). No prior studies have evaluated the effect of cocaine (or other 
drugs of abuse) on TARP expression or distribution. Finally, we measured the activation of several signaling pathways previously linked to AMPAR plasticity.

\section{Methods}

\subsection{Subjects and surgical procedures}

All procedures were approved by the Rosalind Franklin University of Medicine and Science Animal Care and Use Committee. Ninety-five Male Sprague Dawley rats (Harlan; 250$275 \mathrm{~g}$ ) were individually housed (12:12 dark/light). All self-administration sessions were conducted in the dark phase of the cycle with food and water available continually. For catheter implantation, rats were anesthetized with isoflurane gas (Henry Schein, Melville, $\mathrm{NY}$ ) and given the analgesic banamine ( $2 \mathrm{mg} / \mathrm{kg}$ s.c.) prior to surgery. A silastic catheter (Plastics one, Roanoke, VA) was inserted into the right jugular vein, passed under the skin over the right shoulder and fixed in the mid-scapular region. Rats were given 7 days to recover from surgery prior to beginning self-administration. During this time, catheters were flushed every $1-2$ days with sterile saline $(0.1 \mathrm{ml}, 0.9 \%)$.

\subsection{Cocaine self-administration}

Seven days after surgery, rats began self-administration sessions. Sessions $(6 \mathrm{~h})$ were conducted once per day for 10 consecutive days, as in our previous study (Conrad et al., 2008). Self-administration chambers (MED Associates, St. Albans, VT) were located within sound and light attenuating cabinets and were equipped with 2 nose-poke ports located on opposite sides of the chamber, $2 \mathrm{~cm}$ above the floor. Responding in one port (active) resulted in the delivery of an intravenous infusion of cocaine $(0.5 \mathrm{mg} / \mathrm{kg}$ in $32 \mu \mathrm{l}$; Coc-SA) or saline ( $32 \mu \mathrm{l} /$ infusion; Sal-SA) and the illumination of a cue light inside the port. Responses in the second port (inactive) had no consequences. Infusions were delivered on a fixed ratio 1 schedule with a $10 \mathrm{sec}$ time out for the first 10 infusions or first hour (whichever occurred first) followed by a $30 \mathrm{sec}$ time out for the remainder of the session. The number of responses in the active and inactive ports and the number of infusions obtained were recorded throughout each session. Additional handled control rats (Han) were treated in an identical manner as self-administration rats, except they were not exposed to the self-administration chambers. Instead, after recovery from catheter implantation surgery, they were brought to holding cages away from their colony room where they remained for 6 $\mathrm{h}$ before being returned home. This was repeated on 10 consecutive days. These rats were also flushed with saline before and after being placed in the holding cages. Thus, handled controls rats experienced the same surgery, recovery, time away from the colony and handling as self-administration groups. Comparisons between Coc-SA, Sal-SA and Han groups were made for electrophysiological experiments. Comparisons between Coc-SA and Han groups were used in the lysed synaptosomal membrane (LP1) fraction. For all other subcellular fractionation experiments and biotinylation experiments, comparisons were made between Coc-SA and Sal-SA groups. Sal-SA and Han control groups were used interchangeably because no differences between these groups were found in electrophysiological experiments assessing the presence of CP-AMPARs (see Section 3.2). Furthermore, in biochemical studies, levels of GluA1 and GluA2 proteins in various fractions did not differ between these two groups (data not shown). Similar Han control groups have been used in previous studies (Ferrario et al., 2005; Briand et al., 2008a,b). For biochemical studies, tissue was collected on WD1, WD35 or WD45 following the last selfadministration or handling session. Electrophysiological studies were conducted on WD30-33. Details of groups compared, $\mathrm{N}$ values and withdrawal times are provided below following the detailed methods for each type of experiment. 


\subsection{Whole-cell patch-clamp recordings}

Whole-cell patch-clamp recordings were conducted in the presence of NMDAR (APV) and $\mathrm{GABA}_{\mathrm{A}} \mathrm{R}$ (picrotoxin) antagonists as previously described (Conrad et al., 2008). Briefly, the rats were anesthetized with chloral hydrate $(400 \mathrm{mg} / \mathrm{kg}$, i.p.) before being decapitated. Brains were rapidly removed into ice-cold artificial cerebral spinal fluid (aCSF) containing (in mM): $125 \mathrm{NaCl}, 25 \mathrm{NaHCO}_{3}, 12.5$ glucose, $3.5 \mathrm{KCl}, 1.25 \mathrm{NaH}_{2} \mathrm{PO}_{4}, 0.5 \mathrm{CaCl}_{2}, 3$ $\mathrm{MgCl}_{2}, 0.05 \mathrm{APV}$, and 0.05 picrotoxin (pH 7.45, 295-305 mOsm). Coronal slices (300 $\mu \mathrm{m}$ thick) containing the NAc were cut in ice-cold aCSF with a Vibratome, and incubated in warm $\left(\sim 35^{\circ} \mathrm{C}\right)$ aCSF solution constantly oxygenated with $95 \% \mathrm{O}_{2}-5 \% \mathrm{CO}_{2}$ for at least 60 min before recording. In the recording aCSF (delivered at $2 \mathrm{ml} / \mathrm{min}$ ), $\mathrm{CaCl}_{2}$ was increased to $2 \mathrm{mM}$ and $\mathrm{MgCl}_{2}$ was decreased to $1 \mathrm{mM}$. Patch pipettes (6-9 M $\Omega$ ) were pulled from 1.5 $\mathrm{mm}$ borosilicate glass capillaries (WPI, Sarasota, FL) with a horizontal puller (Model P97, Sutter Instrument, Novato, CA), and filled with a solution containing $0.125 \%$ Neurobiotin and (in mM): 140 Cs-gluconate, 10 HEPES, $2 \mathrm{MgCl}_{2}$, $3 \mathrm{Na}_{2}$-ATP, $0.3 \mathrm{GTP}, 0.1$ spermine, 1 QX-314 (pH 7.3, 280-285 mOsm). All chemicals and drugs were purchased from SigmaAldrich. Experimental groups used for patch-clamp recording studies: Han ( $\mathrm{N}=6$ cells from 3 rats), Sal-SA ( $\mathrm{N}=5$ cells from 2 rats), Coc-SA WD30-33 ( $\mathrm{N}=5$ cells from 2 rats).

\subsection{Tissue collection}

One, 35, or 45 days after the last self-administration session (or transport to holding cages for Han group), rats were decapitated and bilateral samples of the NAc (core and shell) were rapidly dissected from a $2 \mathrm{~mm}$ coronal section obtained using a brain matrix (Activational Systems, Warren, MI).

\subsection{Preparation of LP1 fraction and postsynaptic density fraction (PSD)}

The subcellular fractionation method used to obtain these fractions was adapted from Goel et al. (2006). NAc tissue was homogenized (Wheaton Potter-Elvehjem Tissue Grinders, Fisher Scientific, Pittsburgh, PA) in HEPES-buffered sucrose (0.32 M sucrose, $4 \mathrm{mM}$ HEPES, pH 7.4) containing 2 mM EGTA, $50 \mathrm{mM} \mathrm{NaF}, 10 \mathrm{mM}$ PPi, $1 \mathrm{mM} \mathrm{NaOV}, 1 \mathrm{uM}$ okadaic acid, $1 \mathrm{mM}$ phenylmethyl sulfonyl fluoride (PMSF), $1 \mathrm{uM}$ microcystin-LF and $1 \mathrm{X}$ protease inhibitor cocktail set 1 (Calbiochem, Darmstadt, Germany). The homogenate was centrifuged $\left(800 \times \mathrm{g}, 10 \mathrm{~min}, 4^{\circ} \mathrm{C}\right)$ to remove the pelleted nuclear fraction $(\mathrm{P} 1)$. The resulting supernatant $(\mathrm{S} 1)$ was centrifuged $\left(10,000 \times \mathrm{g}, 15 \mathrm{~min}, 4^{\circ} \mathrm{C}\right)$ to yield a crude membrane fraction (P2) which was washed by resuspending in HEPES-buffered sucrose containing protease and phosphatase inhibitors and centrifuging again. The washed $\mathrm{P} 2$ fraction was lysed hypo-osmotically with cold $4 \mathrm{mM}$ HEPES (pH 7.4) with inhibitors and centrifuged $\left(25,000 \times \mathrm{g}, 20 \mathrm{~min}, 4^{\circ} \mathrm{C}\right)$ to yield the LP1 fraction, which was re-suspended in HEPES-buffered sucrose and stored at $-80^{\circ} \mathrm{C}$. Experimental groups used for analysis of the LP1 fraction: Han (N=10) and Coc-SA WD45 (N=9).

For PSD preparation, the LP1 was re-suspended in HEPES-buffered sucrose with inhibitors and run on a discontinuous sucrose gradient $(1.2 \mathrm{M}, 1.0 \mathrm{M}$, and $0.8 \mathrm{M}$ sucrose with inhibitors) and centrifuged $\left(125,000 \times \mathrm{g}, 2 \mathrm{~h}, 4^{\circ} \mathrm{C}\right)$. The synaptic plasma membrane fraction (SPM) was collected between $1.0 \mathrm{M}$ and $1.2 \mathrm{M}$ sucrose. The SPM was diluted 2.5 times in 4 $\mathrm{mM}$ HEPES with inhibitors and pelleted by centrifugation $\left(150,000 \times \mathrm{g}, 30 \mathrm{~min}, 4^{\circ} \mathrm{C}\right)$. The SPM pellet was re-suspended in a $0.5 \%$ Triton X-100, HEPES-EDTA solution $(50 \mathrm{mM}$ HEPES, 2 mM EDTA, pH 7.4 with inhibitors), incubated with rotation $\left(15 \mathrm{~min}, 4^{\circ} \mathrm{C}\right)$ and centrifuged $\left(32,000 \times \mathrm{g}, 20 \mathrm{~min}, 4^{\circ} \mathrm{C}\right)$ to pellet the insoluble postsynaptic density fraction (PSD). The PSD fraction was resuspended in Laemmli sample treatment buffer containing $100 \mathrm{mM}$ dithiothreitol (DTT). Samples were then stored at $-80^{\circ} \mathrm{C}$ until used for SDS-PAGE and Western blotting. Experimental groups used for analysis of PSD fraction: Sal-SA WD1 $(\mathrm{N}=9)$, Coc-SA WD1 (N=9), Sal-SA WD45 (N=9), and Coc-SA WD45 (N=7). 


\subsection{Preparation of a fraction enriched for extrasynaptic membranes}

We used a previously described subcellular fractionation procedure (Davies et al., 2007; 2008; Goebel-Goody et al., 2009) that we have validated in our laboratory (Ferrario et al., in press). Each NAc sample was homogenized in $3 \mathrm{ml}$ of sucrose homogenization buffer (10mM HEPES, 0.32M sucrose, $5 \mathrm{mM}$ NaF, $1 \mathrm{mM} \mathrm{NaVO,} 2 \mathrm{mM}$ EDTA, $\mathrm{pH} 7.4$ ) in a glass grinding vessel with a rotating Teflon pestle (Wheaton Overhead Stirrer; 3000 RPM for 12 passes). The homogenate was then processed as described above to yield the $\mathrm{P} 2$ fraction. The $\mathrm{P} 2$ fraction was washed twice with sucrose homogenization buffer and re-suspended in $4 \mathrm{ml}$ of HEPES-buffered sucrose, containing $0.5 \%$ Triton X-100 (0.5\% v/v), using a motorized pellet pestle mixing/grinding rod (Kontes, Vineland, NJ) in an ultracentrifuge tube. The suspension was then incubated with gentle rotation $\left(20 \mathrm{~min}, 4^{\circ} \mathrm{C}\right)$ and centrifuged $(32,000 \times \mathrm{g}, 20 \mathrm{~min})$ to yield the insoluble pellet (enriched for synaptic membranes) and the soluble fraction (enriched for extrasynaptic membranes). Both fractions were used for initial validation studies in tissue from drug-naïve rats (Ferrario et al., in press) but the insoluble fraction was not analyzed for the present experimental groups because it is redundant with the PSD fraction described in Section 2.5. The extrasynaptic membrane fraction was concentrated by adding 8 volumes of cold acetone, incubating overnight $\left(-20^{\circ} \mathrm{C}\right)$, and centrifuging $(3000 \times \mathrm{g})$. The concentrated pellet was solubilized in sucrose-Triton buffer containing $1 \%$ SDS. The samples were stored at $-80^{\circ} \mathrm{C}$. For SDS-PAGE analysis of extrasynaptic membrane fractions, 5 ug of protein per lane was loaded onto gels. Samples were stored at $-80^{\circ} \mathrm{C}$ until analysis. Experimental groups used for analysis of extrasynaptic membranes: Sal-SA WD45 (N=12); Coc-SA WD45 (N=8).

\subsection{Biotinylation}

Bilateral pieces of NAc tissue from each rat were dissected using a brain matrix and chopped into $400 \mu \mathrm{m}$ slices using a McIllwain tissue chopper (The Vibratome Company, O'Fallon, MO). The tissue was added to eppendorf tubes containing ice-cold aCSF with 1 $\mathrm{mM}$ sulfo-NHS-S-S-Biotin (Thermo Scientific, Rockford, IL) and incubated at $4^{\circ} \mathrm{C}$ with gentle agitation for $30 \mathrm{~min}$. Samples were then incubated at $4^{\circ} \mathrm{C}$ for $10 \mathrm{~min}$ in glycine (100 $\mathrm{mM}$ ) to quench the reaction. The tissue was pelleted, re-suspended in ice-cold lysis buffer [25 mM HEPES pH 7.4, $500 \mathrm{mM} \mathrm{NaCl}, 2$ mM EDTA, $20 \mathrm{mM} \mathrm{NaF}, 10 \mathrm{mM} \mathrm{NaPPi}, 1 \mathrm{mM}$ PMSF, $0.1 \%$ NP-40 (v/v), 1mM NaOV, 1 uM okadaic Acid, 1 uM microsystin-LF, $1 \mathrm{X}$ protease inhibitor cocktail (Calbiochem; 539131)], sonicated, and stored at $-80^{\circ} \mathrm{C}$ as described previously for protein crosslinking experiments (Boudreau and Wolf, 2005; Ferrario et al., 2010). Biotinylation and protein crosslinking experiments are identical except for the fact that different reagents (sulfo-NHS-S-S-Biotin and BS ${ }^{3}$, respectively), are used to selectively modify cell surface proteins. Procedures for purifying biotinylated proteins were adapted from Thermo Scientific product instructions (http://www.piercenet.com/files/0682as4.pdf). Protein concentrations were determined using the Bradford Assay. An aliquot of each NAc sample $(100 \mu \mathrm{g})$ was added to $37.5 \mu 1$ of high capacity NeutrAvidin agarose beads (Cat. No. 29204, Thermo Scientific) and incubated overnight at $4^{\circ} \mathrm{C}$ on an end-over-end rotator. Biotinylated proteins bound to NeutrAvidin beads (bound fraction) were isolated from the nonbiotinylated (unbound) fraction by centrifugation (3,000 RPM, $1 \mathrm{~min}$ ) and washed several times in 1X PBS. The biotinylated fraction was then dissolved in Laemmli sample buffer with DTT $(100 \mathrm{mM})$ and heated at $97^{\circ} \mathrm{C}$ for $3 \mathrm{~min}$ to release the biotinylated proteins from the beads. The samples were then spun at 10,000 RPM for 5 min on a centrifugal filter unit $(0.45 \mu \mathrm{m}$, \#UFC30HV00, Millipore, Billerica, MA) to remove the NeutrAvidin beads from the solution. The samples were then used for immunoblotting as described in Section 2.8. Experimental groups used for analysis of biotinylated tissue: Sal-SA WD35 (N=12); Coc-SA WD35 (N=9). 


\subsection{SDS-PAGE and immunoblotting}

All samples were heated at $70^{\circ} \mathrm{C}$ for $10 \mathrm{~min}$ in Laemmli sample treatment buffer with $100 \mathrm{mM}$ DTT and then processed for SDS-PAGE and immunoblotting as described previously (Ferrario et al., 2010) using the following primary antibodies: GluA1 (1:1000, PA1-37776, Thermo Scientific or 1:1000, AB1504 or MAB2263, Millipore); pS845 GluA1 (1:500, p1160-845, PhosphoSolutions, Aurora, CO; or 1:500, 2491-1, Epitomics, Burlingame, CA); GluA2 (1:200, 75-002, UC Davis/NIH NeuroMab Facility, Davis, CA or 1:1000, AB1768, Millipore); GluA3 (1:500, 3437, Cell Signaling, Danvers, MA); $\gamma 2$ (1:1000, 1505-STAR, PhosphoSolutions); $\gamma 4$ (1:1000, AB5795, Millipore); PSD-95 (1:20,000, 75-028, UC Davis/NIH NeuroMab Facility); CaMKII $\alpha$ (1:20,000, MAB8699, Millipore); CaMKII $\beta$ (1:500, ab34703; AbCam, Cambridge, MA), pCaMKII $\alpha / \beta$ (1:5000, p1005-286, PhosphoSolutions); total ERK1/2 (1:10,000, AB3053, Millipore); pERK1/2 (1:10,000, AB3826, Millipore). Total and phospho-CaMKI antibodies were the generous gift of Dr. Naohito Nozaki (Department of Biochemistry and Molecular Biology, Kanagawa Dental College, Kanagawa, Japan). Membranes were washed in TBS-T solution, incubated at RT for 60 min with HRP-conjugated anti-rabbit or mouse IgG (1:10,000; Invitrogen, Carlsbad, CA), washed with TBS-T, and rinsed with $\mathrm{ddH}_{2} \mathrm{O}$. Membranes were then immersed in chemiluminescence (ECL) detecting substrate (GE Healthcare, Piscataway, NJ). Images of immunoblots were taken on film and quantified using Total Lab (Life Sciences Analysis Essentials). A background value was obtained and diffuse densities for bands of interest in each lane were determined. Because the PSD sample is solubilized directly in SDS, measures of protein concentration in the PSD fraction were unreliable. Therefore, PSD samples were loaded according to volume. All other samples were loaded according to protein concentration. For LP1 and biotinylated (surface) samples, diffuse densities were normalized to total protein in the lane determined by Ponceau-S stain. For data obtained using extrasynaptic membrane fractions, diffuse densities were normalized to $\mu \mathrm{g}$ of protein loaded as described previously (Ferrario et al., in press) because Ponceau-S staining was too weak. Comparisons were made between experimental and control groups using one-way ANOVAs and unpaired t-tests when appropriate. In all cases, Coc-SA groups were compared to a Sal-SA or Han control group killed on the same day, in order to avoid variability due to potential differences between control groups (e.g., related to age or duration of single housing). Data are presented as mean \pm S.E.M. expressed as percent of control. For some proteins, we were unable to quantify immunoreactivity for some lanes due to an unclear band, smudge on the blot or air bubble obstructing the signal. Therefore, the $\mathrm{N}$ for western blotting data may vary from the total number of rats treated. Degrees of freedom are given throughout so that $\mathrm{N}$ can be determined.

\section{Results}

\subsection{Self-administration}

Rats self-administered cocaine for $6 \mathrm{~h} /$ day for 10 days, as in our previous study (Conrad et al., 2008). All of these rats (Coc-SA groups) readily acquired cocaine self-administration and no significant differences in drug intake were found between different cohorts of rats (data not shown). Controls either self-administered saline (Sal-SA groups) or were treated identically to Sal-SA rats except for exposure to the self-administration chamber (Han groups); see Methods for more details. Fig. 1A shows the average number of infusions of cocaine (closed squares) or saline (open circles) taken per session from all four selfadministration cohorts.

\subsection{Electrophysiological demonstration of CP-AMPARs in NAc of Coc-SA rats on WD30-33}

After prolonged (42-47 days) but not short ( 1 day) withdrawal from the same cocaine selfadministration used herein, we demonstrated that CP-AMPARs are incorporated into 
excitatory synapses on medium spiny neurons of the rat NAc core (Conrad et al., 2008). In the current study, we confirmed these results by randomly selecting Han, Sal-SA and CocSA rats from one cohort of rats destined for biochemical studies. NAc slices were obtained from these rats on WD30-33 and used for whole-cell patch-clamp recordings of medium spiny neurons in the NAc core. The presence of CP-AMPARs was evaluated from the rectification index (RI), defined as the ratio of evoked excitatory postsynaptic currents (EPSCs) recorded at $-70 \mathrm{mV}$ and $+40 \mathrm{mV}$. Both CP- and CI-AMPARs contribute to EPSC $_{-70 \mathrm{mV}}$ whereas only CI-AMPARs are responsible for $\mathrm{EPSC}_{+40 \mathrm{mV}}$ due to voltagedependent block of CP-AMPARs by intracellular polyamines. Thus, an increase in the RI indicates a higher synaptic content of CP-AMPARs. As expected from our past results, neurons from all Coc-SA rats showed a significantly higher RI than neurons from Sal-SA and Han groups (Fig. 1B; one-way ANOVA: $\mathrm{F}_{(1,2)}=16.6$, $\mathrm{p}<.001$; post-hoc Han vs COCSA and SAL-SA vs Coc-SA: $p$ values <.0001). These data confirm that the cocaine selfadministration regimen used here reliably leads to incorporation of CP-AMPARs into NAc synapses and that these receptors can be detected as early as WD30. It should be noted that no differences were observed between neurons recorded from Sal-SA and Han control groups.

\subsection{Analysis of AMPAR levels in PSD and LP1 fractions prepared from the NAC}

Based on electrophysiological results indicating a contribution of CP-AMPARs to synaptic currents after prolonged withdrawal, and biochemical data indicating that these receptors are GluA1-containing (Conrad et al., 2008), we predicted that Coc-SA rats should show an increase in GluA1 protein in the PSD fraction. To test this, we prepared PSD fractions from the NAc of four experimental groups: Sal-SA WD1, Sal-SA WD45, Coc-SA WD1 and CocSA WD45. To our surprise, no significant differences in GluA1 total protein levels were found. In fact, a slight decrease in GluA1 protein in the PSD was detected in the Coc-SA WD45 group (Fig. 2A). In addition, no changes in GluA2 or GluA3 protein levels in the PSD were evident (Fig. 2C,D). Next we examined two TARPs, $\gamma 2$ and $\gamma 4$, which we have previously shown to be enriched in synaptic and extrasynaptic membranes, respectively, in the NAc of drug-naïve adult rats (Ferrario et al., in press). The Coc-SA WD45 group showed a trend towards decreased $\gamma 2$ levels in the PSD (Fig. 2B, inset), whereas $\gamma 4$ could not be detected in the PSD (data not shown), consistent with its primarily extrasynaptic location in the NAc (Ferrario et al., in press). Interestingly, $\gamma 2$ levels were correlated with GluA1 levels, but not with GluA2 or GluA3 levels, in all groups. Accordingly, the loss of GluA1 in the Coc-SA WD45 group was accompanied by a similar loss of $\gamma 2$ (Fig. 2B; r=.68, $\mathrm{p}<.05$ ). Given that CP-AMPARs are readily detected in NAc synapses of "incubated rats" using electrophysiological techniques (Fig. 1B; Conrad et al., 2008) and that increases in cell surface and total GluA1 have also been detected in these rats (Conrad et al., 2008 and below), we propose that the decrease in GluA1 in the PSD fraction is due to weak anchoring of CP-AMPARs at the synapse compared to GluA2-containing AMPARs, resulting in their loss during the preparation of the PSD fraction.

To evaluate this possibility, we prepared an LP1 fraction, hypothesizing that loosely anchored receptors would be retained in this cruder membrane fraction (which has not been exposed to detergent; see Methods). Consistent with our earlier findings (Conrad et al., 2008), GluA1 protein levels in the LP1 fraction were significantly increased on WD45 in the NAc of the Coc-SA group compared to Han controls (Fig. $3 \mathrm{~A} ; \mathrm{t}_{17}=1.7$, $\mathrm{p}<.05$ ). Levels of the TARPs $\gamma 2$ and $\gamma 4$ were also elevated in the LP1 fraction of the Coc-SA group, although these trends did not reach statistical significance (Fig. 3B). Furthermore, GluA2 levels were unaltered (Fig. 3C) whereas GluA3 levels were decreased (Fig. 3D; $\mathrm{t}_{17}=2.1, \mathrm{p}=0.05$ ). These data are consistent with the addition of GluA1-containing CP-AMPARs (and associated TARPs) to synaptic membranes during incubation. Furthermore, they support our hypothesis 
that the decrease in GluA1 in the PSD fraction of the Coc-SA WD45 group was a result of steps leading to PSD purification.

\subsection{Analysis of AMPAR surface expression in the NAc using biotinylation}

In our initial study (Conrad et al., 2008), we found an increase in surface expression of GluA1 (but not GluA2) in Coc-SA rats on WD45 using a BS ${ }^{3}$ protein crosslinking assay. We wanted to confirm this result in the present study and also evaluate surface expression of pS845 GluA1 (based on the role of S845 phosphorylation in the insertion of GluA1 into extrasynaptic regions of the plasma membrane; see Discussion) and the TARPs $\gamma 2$ and $\gamma 4$. Unfortunately, despite advantages of the $\mathrm{BS}^{3}$ assay with respect to accuracy and efficiency (Boudreau and Wolf, 2005), we could not accomplish our present goals using this assay because phospho-specific GluA1 antibodies and TARP antibodies do not recognize their targets after $\mathrm{BS}^{3}$ crosslinking (data not shown). As an alternative approach, we biotinylated NAc tissue from Coc-SA and Sal-SA groups killed on WD35. The biotinylated fraction, containing surface-expressed proteins, was immunoblotted using GluA1 and GluA2 antibodies. Cell surface GluA1 was significantly increased in the Coc-SA compared to the Sal-SA group (Fig. 4A; $\mathrm{t}_{16}=2.8$, p $<.05$ ), while total GluA2 was not changed (Fig. 4A). These data confirm previous $\mathrm{BS}^{3}$ crosslinking results indicating an increase in cell surface GluA1 but not GluA2 in the Coc-SA group (WD45; Conrad et al., 2008) and are consistent with electrophysiological evidence for CP-AMPARs on WD30-33 (Fig. 1B) and the selective increase in GluA1 protein in the LP1 fraction on WD45 (Fig. 3). We note that the increase in surface GluA1 detected with biotinylation on WD35 is smaller than the increase found in our prior $\mathrm{BS}^{3}$ crosslinking studies. Thus, GluA1 surface values for individual rats in the biotinylation experiment ranged from 109-164\% of control, whereas values in the prior crosslinking experiments ranged from 129-304\% of control (4 experimental cohorts; Conrad et al., 2008). Differences in the magnitude of the GluA1 increase could be due to differences in tissue processing between biotinylation and $\mathrm{BS}^{3}$ crosslinking, the GluA1 antibody used (the GluA1 antibody employed in Conrad et al., 2008 was no longer useable at the time the present experiments were conducted), or the withdrawal day (WD30-33 versus WD42-47; however it should be noted that the RI did not differ between these withdrawal times, as shown in Fig. 1B). Total drug intake did not vary significantly between the Coc-SA cohorts in the present study and in Conrad et al. (2008).

Interestingly, in addition to an increase in surface GluA1 on WD35, immunoblotting analysis of the biotinylated fraction with a phospho-specific antibody revealed a significant increase in pS845 GluA1 levels in the Coc-SA group compared to the Sal-SA group (Fig. $4 \mathrm{~A} ; \mathrm{t}_{15}=2.7, \mathrm{p}<.05$ ). Because both surface GluA1 and pS845GluA1 increased in the Coc-SA group, their ratio (pS845 GluA1/total GluA1) did not differ between groups (Fig. 4A). These results suggest that new GluA1-containing AMPARs added to the cell surface during cocaine withdrawal are phosphorylated on serine 845. Surface expression of $\gamma 4$ was also significantly increased in the Coc-SA group compared to the Sal-SA group (Fig. 4B; $\mathrm{t}_{17}=$ $2.4, p<.05$ ), whereas $\gamma 2$ levels were unchanged (Fig. 4B). This change in $\gamma 4$ and not $\gamma 2$ levels is particularly interesting considering that $\gamma 2$ moved in parallel to GluA1 in the PSD fraction and that $\gamma 4$ is not readily detectable in synaptic membranes in the NAc (Ferrario et al., in press; see Discussion)

\subsection{Analysis of AMPAR subunits in extrasynaptic membranes from the NAC}

The biotinylation studies described in Section 3.4 show that GluA1-containing AMPARs (phosphorylated at S845) increase on the cell surface after cocaine withdrawal, but this approach does not discriminate between GluA1 located at synaptic versus extrasynaptic sites. Electrophysiological data indicate that some of the new CP-AMPARs are found in synapses after cocaine withdrawal, but the extrasynaptic accumulation of CP-AMPARs 
could contribute to the observed increase in surface and LP1 levels of GluA1. Extrasynaptic CP-AMPARs are also of interest because they may supply the synaptic CP-AMPAR pool (see Discussion). To assess the possibility that some CP-AMPARs accumulate at extrasynaptic sites, we used a previously described subcellular fractionation procedure to isolate an extrasynaptic membrane-enriched fraction (Davies et al., 2007, 2008; GoebelGoody et al., 2009). We have previously validated this procedure in our own laboratory by analyzing levels of marker proteins for different subcellular compartments. For example, synaptic markers [PSD-95 and $\mathrm{Ca}^{2+} /$ calmodulin-dependent protein kinase II (CaMKII)] are virtually undetectable in extrasynaptic membranes. In addition, we used this protocol to demonstrate that extrasynaptic membranes from the NAc of drug-naïve rats contain GluA1-3, albeit at lower levels than found in synaptic membranes, and that homomeric GluA1 receptors can be detected in extrasynaptic membranes (Ferrario et al., in press).

Fig. 5 shows immunoblotting results obtained using extrasynaptic membranes from the NAc of Coc-SA and Sal-SA groups killed on WD45. Although GluA1 levels in this fraction did not increase significantly in the Coc-SA WD45 group, we did find a significant increase in the ratio of pS845 GluA1 to total GluA1 protein levels (Fig. 5; $\mathrm{t}_{15}=2.1$, p<.05). Taken along with the increase in GluA1 protein on the surface and in the LP1 fraction, these data may suggest an increase in the fraction of extrasynaptic GluA1-containing AMPARs primed for synaptic insertion by S845 phosphorylation (see Discussion).

\subsection{Analysis of signaling pathways in NAc PSD fractions}

Using the same PSD fractions used for analysis of AMPAR subunits (Fig. 2), we examined several protein kinases that have been linked to AMPAR plasticity. We began with CaMKII because of its critical role in AMPAR synaptic insertion (Hayashi et al., 2000). In the PSD fraction, the ratio of phosphorylated CaMKII (Thr286) to total CaMKII was significantly increased in the Coc-SA WD45 group compared to the Sal-SA WD45 group; this was observed for both $\alpha$ and $\beta$ CaMKII isoforms (Fig. 6A; $\mathrm{t}_{14}=2.1, \mathrm{p}<.05$; Fig. 6B; $\mathrm{t}_{14}=2.2, \mathrm{p}<$. 05). The increased ratios in the Coc-SA WD45 group reflected small increases in phosphorylated CaMKII combined with small decreases in total CaMKII (data not shown). We also evaluated CaMKI because it has been implicated in synaptic insertion of CPAMPARs in the hippocampus (Guire et al., 2008;Fortin et al., 2010), but no differences in CaMKI phosphorylation or total levels were observed between experimental groups (Fig. 6C). Next we examined extracellular signal-regulated kinase (ERK) because its activation also plays a role in AMPAR synaptic incorporation (Zhu et al., 2002). In the PSD fraction, total levels of ERK1 and ERK2 were not significantly altered by cocaine exposure, though there was a trend towards an increase in both isoforms in the Coc-SA WD1 group compared to control (Fig. 7A). Similarly, there was a trend towards an increase in pERK2 in the CocSA WD1 group, as well as a smaller trend in the Coc-SA WD45 group (Fig. 7B). The ratio of pERK2/total ERK2 protein was significantly increased in PSD fractions from Coc-SA groups on both WD1 and WD45 compared to Sal-SA groups (Fig. 7C; WD1, $\mathrm{t}_{16}=1.7, \mathrm{p}<.05$; WD45, $\mathrm{t}_{14}=1.8, \mathrm{p}<.05$ ) The $\mathrm{pERK} 1$ signal in the PSD fraction was too weak to reliably quantify.

\section{Discussion}

In drug-naïve adult rats, NAc synapses contain very low levels of CP-AMPARs (Conrad et al., 2008; Reimers et al., 2010). However, GluA1-containing CP-AMPARs (homomeric GluA1 or GluA1A3 receptors) accumulate in NAc synapses after withdrawal from extended access cocaine self-administration (Conrad et al., 2008). Most importantly, these CPAMPARs mediate the expression of incubated cue-induced cocaine seeking on WD45. This CP-AMPAR dependent enhancement of drug seeking behavior may be due to an increase in the reactivity of NAc medium spiny neurons to glutamate as a result of the higher 
conductance of CP-AMPARs compared to the CI-AMPARs that normally dominate in NAc synapses. Incorporation of only a small number of these high conductance CP-AMPARs can significantly increase synaptic strength (Guire et al., 2008).

In humans, it is relatively common for cocaine users to become abstinent for a month or so due to incarceration or hospitalization (Reichel and Bevins, 2009), a period of time that is sufficient for incubation (Lu et al., 2004) and synaptic incorporation of CP-AMPARs in the NAc in rats (present results). If incubation occurs in humans, as indicated by a recent study (Bedi et al., 2010), and if addition of CP-AMPARs also participates in enhanced drug seeking and craving in human cocaine addicts, then blocking or removing CP-AMPARs should help a recovering addict remain abstinent. Unfortunately, the known CP-AMPAR blockers are neurotoxins, so other strategies must be found. To aid in the development of such strategies, it is important to understand where CP-AMPARs are expressed in NAc neurons and what mechanisms enable them to accumulate in these synapses (from which they are largely excluded under normal conditions). We approached this problem by using subcellular fractionation and biotinylation to analyze AMPAR subunit and TARP distribution in the NAc of "incubated rats" on WD30-45.

\section{Subcellular location of CP-AMPARs in the NAc of "incubated rats"}

Consistent with prior protein crosslinking results (Conrad et al., 2008), the LP1 and biotinylation studies presented here indicated increased surface expression of GluA1 but not GluA2 in the NAc of Coc-SA rats on WD35, suggesting increased surface expression of CPAMPARs. Confirming this, electrophysiological studies detected inwardly rectifying AMPAR excitatory postsynaptic currents (EPSCs) on WD30-33. Inward rectification is a hallmark of CP-AMPARs (Cull-Candy et al., 2006). We had previously used electrophysiological approaches to demonstrate the presence of CP-AMPARs on WD42-47, although biochemical results suggested that they were present even earlier in withdrawal (Conrad et al., 2008). In a mouse study, Mameli et al. (2009) detected CP-AMPARs in the NAc shell on WD35 after a similar cocaine self-administration regimen. Because these electrophysiological experiments assess synaptic responses, they establish that at least some of the new CP-AMPARs detected biochemically are located in synapses. However, our results suggest that synaptic CP-AMPARs are more loosely anchored to the PSD than GluA1A2-containing AMPARs, because increased GluA1 levels were detectable in a LP1 fraction from Coc-SA rats on WD45 (i.e., a fraction not exposed to detergent) whereas levels of GluA1 (and $\gamma 2$ ) were slightly decreased in a PSD fraction from identically treated rats.

To determine if extrasynaptic CP-AMPAR levels are also increased, we measured GluA1 in a fraction enriched for extrasynaptic membranes. Starting with NAc tissue from adult drugnaïve rats, we showed previously that GluA1-3 subunits are detected in this fraction, albeit at lower levels than in synaptic membranes, and that some extrasynaptic AMPARs are homomeric GluA1 receptors (Ferrario et al., in press). Here we found that GluA1 levels in extrasynaptic membranes were not significantly increased in the Coc-SA group compared to the Sal-SA group on WD45 (although GluA1 phosphorylation in extrasynaptic membranes of the Coc-SA group was significantly increased, as discussed below). It is well established that AMPARs diffuse in the extrasynaptic membrane, and between extrasynaptic and synaptic areas, although their mobility decreases substantially once they enter synapses (e.g., Borgdoff and Choquet, 2002; Heine et al., 2008; Opazo et al., 2010). Thus, our finding of no significant change in total GluA1 in extrasynaptic membranes, but an increase in CPAMPAR levels in synapses, may indicate more efficient transfer of CP-AMPARs from extrasynaptic to synaptic pools in the Coc-SA group (although their anchoring to the synapse may be relatively weak; see previous paragraph). However, we cannot exclude the possibility that a functionally significant increase in extrasynaptic GluA1 occurred which 
was below the limit of detection of our biochemical techniques. Total surface levels of GluA1, measured with biotinylation, were increased $\sim 40 \%$ above control (Fig. 4). If this increase is split between synaptic and extrasynaptic GluA1 pools, then the magnitude of the change in the extrasynaptic pool might be very small, particularly since GluA1 is more abundant in synaptic membranes than extrasynaptic membranes (Ferrario et al., in press). Indeed, a small trend towards an increase in extrasynaptic GluA1 is apparent in Fig. 5. Ultimately, this issue could be further examined using electrophysiological techniques.

\section{Cocaine alters distribution of TARPs in the NAc}

Type I TARPs $(\gamma 2, \gamma 3, \gamma 4$ and $\gamma 8)$ are auxiliary AMPAR subunits that associate with AMPARs early in their biosynthesis and then regulate both their trafficking and channel function (Ziff, 2007; Kato et al., 2010). $\gamma 2$ and $\gamma 4$ are expressed in the NAc, although interestingly $\gamma 2$ is enriched in synaptic membranes but present in extrasynaptic membranes, whereas $\gamma 4$ is mainly expressed in extrasynaptic membranes (Ferrario et al., in press). In fact, $\gamma 4$ cannot be detected in PSD fractions from either drug-naïve rats (Ferrario et al., in press) or Coc-SA rats (present results). The presence of $\gamma 2$ and $\gamma 4$ in our NAc samples is consistent with prior studies showing $\gamma 2$ and $\gamma 4$ in the NAc and other striatal regions (Klugbauer et al., 2000; Sharp et al., 2001; Tomita et al., 2003; Fukaya et al., 2005). These studies also detected $\gamma 3$ and $\gamma 8$ in striatal tissue. However, lack of a selective antibody precluded our investigation of $\gamma 3$, and $\gamma 8$ does not appear to be expressed by NAc medium spiny neurons, at least in primary cultures (C.R. Ferrario and M.E. Wolf, unpublished observations). Two subfamilies of Type I TARPS are now recognized: Type Ia ( $\gamma 2$ and $\gamma 3)$ and Type $\mathrm{Ib}(\gamma 4$ and $\gamma 8)$. Both subfamilies regulate AMPAR trafficking, but Type Ib TARPs produce a more dramatic enhancement of AMPAR currents (Kato et al., 2010), suggesting functional consequences of the different distribution of $\gamma 2$ and $\gamma 4$ in the NAc (Ferrario et al., in press).

Our results provide the first evidence that TARPs are affected by cocaine exposure. First, indirect evidence from the PSD fraction (see Section 3.3) suggests that the new CPAMPARs in synapses are associated with $\gamma 2$. However, the Coc-SA group exhibited a trend towards increased $\gamma 2$ and especially $\gamma 4$ in the LP1 fraction, suggesting that some new CPAMPARs contain $\gamma 4$. These may be extrasynaptic CP-AMPARs, since very little $\gamma 4$ is detected in synaptic membranes (see previous paragraph). Furthermore, increased $\gamma 4$ surface expression was found in biotinylated NAc tissue, which includes the extrasynaptic surface AMPAR pool. Further interpretation of our results is difficult because the stoichiometry of TARPs in AMPAR tetramers remains unclear and may be cell specific, and because it is not clear whether a given AMPAR tetramer can contain more than one TARP isoform (see Tomita et al., 2003; Shi et al., 2009; Kim et al., 2010). Despite these questions, given that TARP phosphorylation state regulates AMPAR synaptic targeting (see next section), it is possible that cocaine influences AMPAR trafficking in part through mechanisms that involve TARPs.

\section{Role of GluA1 phosphorylation in CP-AMPAR accumulation}

GluA1 phosphorylation is regulated in concert with synaptic plasticity and influences both channel function and receptor trafficking (Derkach et al., 2007; Shepherd and Huganir, 2007; Lin et al., 2009; Lu et al., 2010). We focused on S845, which is phosphorylated by protein kinase A (Roche et al., 1996; Mammen et al., 1997). Phosphorylation of S845 can increase AMPAR open probability (Banke et al., 2000) although the majority of recent studies have focused on its role in AMPAR trafficking. In NAc neurons, we have shown that GluA1-containing AMPARs are incorporated into synapses via a two-step process. They are first inserted onto the cell surface at extrasynaptic sites, and then translocated into synapses in an NMDA receptor-dependent manner. The first step is accelerated by PKA activation, 
most likely via phosphorylation of S845 in GluA1 (Chao et al., 2002a,b; Mangiavacchi and Wolf, 2004; Sun et al., 2008; for review, see Wolf, 2010b). Studies in other brain regions similarly indicate that PKA phosphorylation of GluA1 primes AMPARs for synaptic insertion (Esteban et al., 2003; Sun et al., 2005; Oh et al., 2006; Gao et al., 2006; Man et al., 2007) and that extrasynaptic surface AMPARs are important for supplying the synapse (Passafaro et al., 2001; Sun et al., 2005; Gao et al., 2006; Yudowski et al., 2007; Heine et al., 2008; Yang et al., 2008; Lin et al., 2009; Makino and Malinow, 2009). Particularly relevant to our study, perisynaptic CP-AMPARs are important for increasing synaptic strength during some types of LTP (Guire et al., 2008; Yang et al., 2010).

Recently, we found that pS845 GluA1 is enriched in extrasynaptic membranes (relative to synaptic membranes) from the NAc of adult drug-naïve rats (Ferrario et al., in press). In the present study, we observed an increase in the pS845 GluA1/total GluA1 ratio in the extrasynaptic membrane fraction from the Coc-SA WD45 group compared to Sal-SA controls. We also observed increased pS845 GluA1 on the cell surface in the Coc-SA WD35 group (biotinylation experiments). These results suggest that a greater portion of the extrasynaptic GluA1 is phosphorylated at S845 in "incubated rats". In light of evidence that S845 phosphorylation primes GluA1-containing AMPARs for synaptic insertion (above), the observed increase in extrasynaptic pS845 GluA1 could play a causal role in the elevation of synaptic CP-AMPAR levels that we observe in electrophysiological studies on WD30-47. Interestingly, a recent study showed that $\mathrm{S} 845$ phosphorylation stabilizes perisynaptic GluA1-containing CP-AMPARs in hippocampus, preventing their degradation (He et al., 2009). However, this would predict an increase in total GluA1 protein in the extrasynaptic pool, which we did not observe, although a small effect cannot be ruled out (see second section of Discussion). An increase in S845 GluA1, in concert with addition of GluA1containing CP-AMPARs to hippocampal synapses, has also been reported $12 \mathrm{~h}$ after discontinuing repeated morphine injections (Billa et al., 2010).

\section{Candidate signaling mechanisms for CP-AMPAR plasticity during incubation}

We studied signaling pathway activation in PSD fractions from Coc-SA rats to learn about mechanisms that may underlie CP-AMPAR accumulation. CaMKII was studied because its activation is required for activity-dependent synaptic insertion of GluA1-containing AMPARs although GluA1 is not the relevant substrate (Hayashi et al., 2000). Instead, recent evidence indicates that activity-dependent translocation of CaMKII to the PSD leads to phosphorylation of $\gamma 2$, facilitating $\gamma 2$ binding to PSD-95; this promotes synaptic retention of $\gamma 2$ and associated GluA1-containing receptors (Opazo et al., 2010). Phosphorylation of $\gamma 2$ may promote its binding to PSD-95 by dissociating $\gamma 2$ from lipid bilayers; the lipid interaction inhibits $\gamma 2$ binding to PSD-95 (Sumioka et al., 2010). Given that we observed an increase in pCaMKII/total CaMKII in the PSD fraction of the Coc-SA WD45 group, it is possible that the mechanism identified by Opazo et al. (2010), activated persistently, could underlie our observations of higher levels of GluA1-containing AMPARs in the LP1 fraction and on the cell surface in the biotinylation experiments $(\gamma 2$ and $\gamma 4$ showed trends towards increases in the LP1 fraction, although only surface $\gamma 4$ increased in the biotinylation experiment). It would be interesting to determine if TARP phosphorylation is increased in the NAc of "incubated rats", but we have been unable to resolve different TARP phosphorylation states in NAc tissue using electrophoresis or other methods and no phospho-specific antibodies are available. It is also possible that the increase in CaMKII activation in the Coc-SA group is a consequence of the presence of CP-AMPARs in the membrane, as they would provide a new source of $\mathrm{Ca}^{2+}$ entry that could lead to CaMKII activation.

Prior work has implicated CaMKII in cellular and behavioral changes involving the NAc that are produced by repeated psychostimulant exposure, but this work has been conducted 
after non-contingent drug treatment (e.g., Pierce and Kalivas, 1997; Pierce et al., 1998; Boudreau et al., 2009; Loweth et al., 2010) or limited access drug self-administration (e.g., Anderson et al., 2008; Loweth et al., 2008; Wang et al., 2010). Interestingly, in the latter experimental situation, cocaine-primed reinstatement was shown to require a rapid CaMKII dependent increase in cell surface GluA1 associated with GluA1 phosphorylation at S831 (Anderson et al., 2008). However the time course of this effect (AMPAR changes were detected $30 \mathrm{~min}$ after the priming injection of cocaine) is markedly different from the extremely persistent increases in GluA1 surface expression (weeks to months) that we are studying in the incubation model. Somewhat more analogous are studies showing that overexpression of CaMKII for several days led to an increase in AMPAR-mediated responses in the NAc (Loweth et al., 2010; Singer et al., 2010), although the time-scale is still quite different.

When comparing our results to studies using other cocaine self-administration procedures, it is important to recognize that we do not know whether CP-AMPAR levels increase in the NAc after prolonged withdrawal from limited access cocaine self-administration (see Wolf and Ferrario, 2010 for more discussion). All of the evidence for CP-AMPAR accumulation has been obtained after withdrawal from extended access cocaine self-administration (Conrad et al., 2008; Mameli et al., 2009; present study). Extended access selfadministration produces different behaviors compared to limited access cocaine selfadministration, suggesting that the two experiences do not produce equivalent neuroadaptations. Based on the behavioral differences, extended access is believed to more closely model the compulsive drug seeking and taking characteristic of addiction than limited access procedures (Ahmed and Koob, 1998; Vanderschuren and Everitt, 2004; Ferrario et al., 2005; Ben-Shahar et al., 2009). It will be interesting to test for CP-AMPARs after prolonged withdrawal from very long duration cocaine self-administration regimens (8-10 weeks); striking individual differences in NAc synaptic plasticity are evident $24 \mathrm{~h}$ after discontinuing such a regimen (Kasanetz et al., 2010).

We also evaluated CaMKI based on evidence that it mediates redistribution of CP-AMPARs from extrasynaptic pools to the synapse during theta-burst stimulation (TBS) induced LTP (Guire et al., 2008) as well as the spine enlargement that accompanies AMPAR synaptic insertion (Fortin et al., 2010). However, we found no evidence for CaMKI activation in the PSD fraction (or LP1; data not shown) of Coc-SA rats. This is not surprising in light of differences between the two situations. Hippocampal LTP is a rapidly occurring form of synaptic strengthening elicited by a relatively discrete stimulus. With some paradigms (e.g., TBS), the initial synaptic strengthening depends on synaptic incorporation of CP-AMPARs but these are replaced within 20-30 min by CI-AMPARs (Plant et al., 2006; Guire et al., 2008). In contrast, in the incubation model, CP-AMPARs are added to NAc synapses over weeks (Conrad et al., 2008), and then remain in synapses for at least 69 days (K.Y. Tseng, unpublished findings). At least from the perspective of timing of onset, this is more reminiscent of homeostatic plasticity than Hebbian plasticity (see Sun and Wolf, 2009 for more discussion) and it is therefore not surprising that different mechanisms underlie CPAMPAR plasticity in these two situations. The time course of our effect also contrasts with studies showing CP-AMPAR synaptic incorporation in other brain regions during the first day after discontinuing cocaine, morphine or benzodiazepine exposure (e.g., Bellone and Lüscher, 2006; Song et al., 2007; Argilli et al., 2008; Billa et al., 2010; Good and Lupica, 2010).

ERK2 activation is involved in many aspects of addiction-related plasticity (Lu et al., 2006; Girault et al., 2007) and prior studies have demonstrated that ERK2 activation accompanies increased cell surface levels of GluA1A2-containing AMPARs in the NAc of rats treated repeatedly with non-contingent cocaine to produce behavioral sensitization (Boudreau et al., 
2007, 2009; Schumann and Yaka, 2009). Here, we found that the ratio of pERK2/total ERK2 was significantly increased in the NAc PSD fraction from Coc-SA rats on both WD1 and WD45. This duration of ERK2 activation is remarkable, although we had previously found ERK2 activation lasting at least 2 weeks in the NAc of cocaine-sensitized rats (Boudreau et al., 2009). It is possible that ERK2 activation plays a role in maintaining GluA1-containing AMPAR upregulation after withdrawal from either non-contingent or contingent cocaine exposure. Interestingly, the correlation between upregulation of GluA1containing AMPARs in the NAc and ERK2 activation is bidirectional: both AMPAR subunit surface expression and pERK2 increase 24 after withdrawal, whereas subsequent reexposure to cocaine normalizes both measures (Boudreau et al., 2007).

\section{Conclusions}

CP-AMPARs are increased in NAc synapses of rats evaluated after withdrawal from extended access cocaine self-administration ("incubated rats"). This is detected as early as WD30-33 and persists at least through WD69 (and perhaps beyond), making it among the more persistent drug-induced neuroadaptations that have been described. Our results suggest that new CP-AMPARs in NAc synapses are loosely tethered to the PSD and may be associated with $\gamma 2$. Increased synaptic levels of CP-AMPARs may result in part from an increase in S845 phosphorylation of GluA1 in extrasynaptic membranes, given that S845 phosphorylation primes GluA1-containing AMPARs for synaptic insertion and extrasynaptic AMPARs supply the synapse. Some of the new extrasynaptic CP-AMPARs are likely associated with $\gamma 4$, rather than $\gamma 2$. The maintenance of CP-AMPARs in synapses across more than a month of withdrawal is accompanied by activation of ERK2; furthermore, CaMKII but not CaMKI is activated on WD45. Future studies should explore a role for additional signaling pathways, and examine how these postsynaptic adaptations may be related to changes in presynaptic glutamate tone (see Wolf, 2010a).

\section{Abbreviations}

$\begin{array}{ll}\text { aCSF } & \text { artificial cerebral spinal fluid } \\ \text { BS }^{3} & \text { bis(sulfosuccinimidyl)suberate } \\ \text { CaMK } & \mathrm{Ca}^{2+} \text { calmodulin-dependent protein kinase } \\ \text { CI-AMPAR and CP-AMPAR } & \mathrm{Ca}^{2+} \text {-impermeable and } \mathrm{Ca}^{2+} \text {-permeable AMPAR } \\ \text { DTT } & \text { dithiothreitol } \\ \text { EPSC } & \text { excitatory postsynaptic current } \\ \text { ERK } & \text { extracellular signal-regulated kinase } \\ \text { pS845 GluR1 } & \text { GluA1 phosphorylated at serine } 845 \\ \text { LP1 } & \text { lysed synaptosomal membranes } \\ \text { NAc } & \text { nucleus accumbens } \\ \text { PSD } & \text { postsynaptic density } \\ \text { TARP } & \text { transmembrane AMPA receptor regulatory protein } \\ \text { WD } & \text { withdrawal day }\end{array}$

\section{Acknowledgments}

These studies were supported by DA015835, DA09621, DA000453 and DA029099 to M.E.W., and Rosalind Franklin University Start-up funds and DA004093 to K.Y.T. C.R.F. was supported by postdoctoral National 
Research Service Award DA024502. We thank Dr. Naohito Nozaki (Department of Biochemistry and Molecular Biology, Kanagawa Dental College, Kanagawa, Japan) for generously providing CaMKI antibodies, Dr. Susumu Tomita (Yale University, New Haven, CT) for helpful discussions and Dr. Michela Marinelli for the use of her equipment.

\section{References}

Ahmed SH, Koob GF. Transition from moderate to excessive drug intake: change in hedonic set point. Science. 1998; 282:298-300. [PubMed: 9765157]

Anderson SM, Famous KR, Sadri-Vakili G, Kumaresan V, Schmidt HD, Bass CE, Terwilliger EF, Cha JH, Pierce RC. CaMKII: a biochemical bridge linking accumbens dopamine and glutamate systems in cocaine seeking. Nat. Neurosci. 2008; 11:344-353. [PubMed: 18278040]

Argilli E, Sibley DR, Malenka RC, England PM, Bonci A. Mechanism and time course of cocaineinduced long-term potentiation in the ventral tegmental area. J. Neurosci. 2008; 28:9092-9100. [PubMed: 18784289]

Banke TG, Bowie D, Lee H, Huganir RL, Schousboe A, Traynelis SF. Control of GluR1 AMPA receptor function by cAMP-dependent protein kinase. J. Neurosci. 2000; 20:89-102. [PubMed: 10627585]

Bedi G, Preston KL, Epstein DH, Heishman SJ, Marrone GF, Shaham Y, de Wit H. Incubation of cueinduced cigarette craving during abstinence in human smokers. Biol. Psychiatry. 2010 Epub Sept. 2.

Bellone C, Lüscher C. Cocaine triggered AMPA receptor redistribution is reversed in vivo by mGluRdependent long-term depression. Nat. Neurosci. 2006; 9:636-641. [PubMed: 16582902]

Ben-Shahar O, Obara I, Ary AW, Ma N, Mangiardi MA, Medina RL, Szumlinski KK. Extended daily access to cocaine results in distinct alterations in Homer 1b/c and NMDA receptor subunit expression within the medial prefrontal cortex. Synapse. 2009; 63:598-609. [PubMed: 19306440]

Billa SK, Liu J, Bjorklund NL, Sinha N, Fu Y, Shinnick-Gallagher, Morón JA. Increased insertion of glutamate receptor 2-lacking $\alpha$-amino-3-hydroxy-5-methyl-4-isoxazole propionic acid (AMPA) receptors at hippocampal synapses upon repeated morphine administration. Mol. Pharmacol. 2010; 77:874-883. [PubMed: 20159947]

Borgdorff AJ, Choquet D. Regulation of AMPA receptor lateral movements. Nature. 2002; 417:649653. [PubMed: 12050666]

Boudreau AC, Ferrario CR, Glucksman MJ, Wolf ME. Signaling pathway adaptations and novel protein kinase A substrates related to behavioral sensitization to cocaine. J. Neurochem. 2009; 110:363-377. [PubMed: 19457111]

Boudreau AC, Reimers JM, Milovanovic M, Wolf ME. Cell surface AMPA receptors in the rat nucleus accumbens increase during cocaine withdrawal but internalize after cocaine challenge in association with altered activation of mitogen-activated protein kinases. J Neurosci. 2007; 27:10621-10635. [PubMed: 17898233]

Boudreau AC, Wolf ME. Behavioral sensitization to cocaine is associated with increased AMPA receptor surface expression in the nucleus accumbens. J. Neurosci. 2005; 25:9144-9151. [PubMed: 16207873]

Briand LA, Flagel SB, Garcia-Fuster MJ, Watson SJ, Akil H, Sarter M, Robinson TE. Persistent alterations in cognitive function and prefrontal dopamine D2 receptors following extended, but not limited, access to self-administered cocaine. Neuropsychopharmacology. 2008a; 33:2969-2980. [PubMed: 18305460]

Briand LA, Flagel SB, Seeman P, Robinson TE. Cocaine self-administration produces a persistent increase in dopamine D2 High receptors. European Neuropsychopharmacology. 2008b; 8:551556.

Chao SZ, Ariano MA, Peterson DA, Wolf ME. D1 dopamine receptor stimulation increases GluR1 surface expression in nucleus accumbens neurons. J. Neurochem. 2002a; 83:704-712. [PubMed: 12390532]

Chao SZ, Lu W, Lee HK, Huganir RL, Wolf ME. D(1) dopamine receptor stimulation increases GluR1 phosphorylation in postnatal nucleus accumbens cultures. J. Neurochem. 2002b; 81:984-992. [PubMed: 12065610] 
Conrad KL, Tseng KY, Uejima JL, Reimers JM, Heng LJ, Shaham Y, Marinelli M, Wolf ME. Formation of accumbens GluR2-lacking AMPA receptors mediates incubation of cocaine craving. Nature. 2008; 454:118-121. [PubMed: 18500330]

Crombag HS, Bossert JM, Koya E, Shaham Y. Context-induced relapse to drug seeking: a review. Philos. Trans. R. Soc. Lond. B. Biol. Sci. 2008; 363:3233-3243. [PubMed: 18640922]

Cull-Candy S, Kelly L, Farrant M. Regulation of $\mathrm{Ca}^{2+}$-permeable AMPA receptors: synaptic plasticity and beyond. Curr. Opin. Neurobiol. 2006; 16:288-297. [PubMed: 16713244]

Davies KD, Alvestad RM, Coultrap SJ, Browning MD. $\alpha$ CaMKII autophosphorylation levels differ depending on subcellular localization. Brain Res. 2007; 1158:39-49. [PubMed: 17559813]

Davies KD, Goebel-Goody SM, Coultrap SJ, Browning MD. Long-term synaptic depression that is associated with GluR1 dephosphorylation but not $\alpha$-amino-3-hydroxy-5-methyl-4isoxazolepropionic acid (AMPA) receptor internalization. J. Biol. Chem. 2008; 283:33138-33146. [PubMed: 18819923]

Derkach VA, Oh MC, Guire ES, Soderling TR. Regulatory mechanisms of AMPA receptors in synaptic plasticity. Nat. Rev. Neurosci. 2007; 8:101-113. [PubMed: 17237803]

Esteban JA, Shi SH, Wilson C, Nuriya M, Huganir RL, Malinow R. PKA phosphorylation of AMPA receptor subunits controls synaptic trafficking underlying plasticity. Nat. Neurosci. 2003; 6:136143. [PubMed: 12536214]

Ferrario CR, Gorny G, Crombag HS, Li Y, Kolb B, Robinson TE. Neural and behavioral plasticity associated with the transition from controlled to escalated cocaine use. Biol. Psychiatry. 2005; 58:751-759. [PubMed: 16098484]

Ferrario CR, Li X, Wang X, Reimers JM, Uejima JL, Wolf ME. The role of glutamate receptor redistribution in locomotor sensitization to cocaine. Neuropsychopharmacol. 2010; 35:818-833.

Ferrario CR, Loweth JA, Milovanovic M, Wang X, Wolf ME. Distribution of AMPA receptor subunits and TARPs in synaptic and extrasynaptic membranes of the adult rat nucleus accumbens. Neurosci. Lett. in press.

Fortin DA, Davare MA, Srivastava T, Brady JD, Nygaard S, Derkach VA, Soderling TR. Long-term potentiation-dependent spine enlargement requires synaptic $\mathrm{Ca}^{2+}$-permeable AMPA receptors recruited by CaM-Kinase I. J. Neurosci. 2010; 30:11565-11575. [PubMed: 20810878]

Fukaya M, Yamazaki M, Sakimura K, Watanabe M. Spatial diversity in gene expression for VDCCgamma subunit family in developing and adult mouse brains. Neurosci. Res. 2005; 53:376383. [PubMed: 16171881]

Gao C, Sun X, Wolf ME. Activation of D1 dopamine receptors increases surface expression of AMPA receptors and facilitates their synaptic incorporation in cultured hippocampal neurons. J. Neurochem. 2006; 98:1664-1677. [PubMed: 16800848]

Girault JA, Valjent E, Caboche J, Hervé D. ERK2: a logical AND gate critical for drug-induced plasticity? Curr. Opin. Pharmacol. 2007; 7:77-85. [PubMed: 17085074]

Goebel-Goody SM, Davies KD, Alvestad Linger RM, Freund RK, Browning MD. Phospho-regulation of synaptic and extrasynaptic N-methyl-D-aspartate receptors in adult hippocampal slices. Neurosci. 2009; 158:1446-1459.

Goel A, Jiang B, Xu LW, Song L, Kirkwood A, Lee HK. Cross-modal regulation of synaptic AMPA receptors in primary sensory cortices by visual experience. Nat. Neurosci. 2006; 9:1001-1003. [PubMed: 16819524]

Good CH, Lupica CR. Afferent-specific AMPA receptor subunit composition and regulation of synaptic plasticity in midbrain dopamine neurons by abused drugs. J. Neurosci. 2010; 30:79007909. [PubMed: 20534838]

Guire ES, Oh MC, Soderling TR, Derkach VA. Recruitment of calcium-permeable AMPA receptors during synaptic potentiation is regulated by CaM-kinase I. J. Neurosci. 2008; 28:6000-6009. [PubMed: 18524905]

Hayashi Y, Shi SH, Esteban JA, Piccini A, Poncer JC, Malinow R. Driving AMPA receptors into synapses by LTP and CaMKII: requirement for GluR1 and PDZ domain interaction. Science. 2000; 287:2262-2267. [PubMed: 10731148] 
He K, Song L, Cummings LW, Goldman J, Huganir RL, Lee H-K. Stabilization of $\mathrm{Ca}^{2+}$-permeable AMPA receptors at perisynaptic sites by GluR1-S845 phosphorylation. Proc. Natl. Acad. Sci. USA. 2009; 106:20033-20038. [PubMed: 19892736]

Heine M, Groc L, Frischknecht R, Béique J-C, Lounis B, Rumbaugh G, Huganir RL, Cognet L, Choquet D. Surface mobility of postsynaptic AMPARs tunes synaptic transmission. Science. 2008; 320:201-205. [PubMed: 18403705]

Isaac JT, Ashby M, McBain CJ. The role of the GluR2 subunit in AMPA receptor function and synaptic plasticity. Neuron. 2007; 54:859-871. [PubMed: 17582328]

Kalivas PW. The glutamate homeostasis hypothesis of addiction. Nat. Rev. Neurosci. 2009; 10:561572. [PubMed: 19571793]

Kasanetz F, Deroche-Gamonet V, Berson N, Balado E, Lafourcade M, Manzoni O, Piazza PV. Transition to addiction is associated with a persistent impairment in synaptic plasticity. Science. 2010; 328:1709-1712. [PubMed: 20576893]

Kato AS, Gill MB, Yu H, Nisenbaum ES, Bredt DS. TARPS differentially decorate AMPA receptors to specify neuropharmacology. Trends Neurosci. 2010; 33:241-248. [PubMed: 20219255]

Kim KS, Yan D, Tomita S. Assembly and stoichiometry of the AMPA receptor and transmembrane AMPA receptor regulatory protein complex. J. Neurosci. 2010; 30:1064-1072. [PubMed: 20089915]

Klugbauer N, Dai S, Specht V, Lacinová L, Marais E, Bohn G, Hofmann F. A family of gamma-like calcium channel subunits. FEBS Lett. 2000; 470:189-197. [PubMed: 10734232]

Lin D-T, Makino Y, Sharma K, Hayashi T, Neve R, Takamiya K, Huganir RL. Regulation of AMPA receptor extrasynaptic insertion by $4.1 \mathrm{~N}$, phosphorylation and palmitoylation. Nat. Neurosci. 2009; 12:879-887. [PubMed: 19503082]

Liu SJ, Zukin RS. $\mathrm{Ca}^{2+}$-permeable AMPA receptors in synaptic plasticity and neuronal death. Trends Neurosci. 2007; 30:126-134. [PubMed: 17275103]

Loweth JA, Baker LK, Guptaa T, Guillory AM, Vezina P. Inhibition of CaMKII in the nucleus accumbens shell decreases enhanced amphetamine intake in sensitized rats. Neurosci. Lett. 2008; 444:157-160. [PubMed: 18694805]

Loweth JA, Singer BF, Baker LK, Wilke GA, Inamine H, Bubula N, Alexander JK, Carlezon WA Jr, Neve RL, Vezina P. Transient overexpression of $\alpha-\mathrm{Ca}^{2+} /$ calmodulin-dependent protein kinase II in the nucleus accumbens shell enhances behavioral responding to amphetamine. J. Neurosci. 2010; 30:939-949. [PubMed: 20089902]

Lu L, Grimm JW, Hope BT, Shaham Y. Incubation of cocaine craving after withdrawal: a review of preclinical data. Neuropharmacology. 2004; 47:214-226. [PubMed: 15464139]

Lu L, Koya E, Zhai H, Hope BT, Shaham Y. Role of ERK in cocaine addiction. Trends Neurosci. 2006; 29:695-703. [PubMed: 17084911]

Lu W, Isozaki K, Roche KW, Nicoll RA. Synaptic targeting of AMPA receptors is regulated by a CaMKII site in the first intracellular loop of GluA1. Proc. Natl. Acad. Sci. USA. 2010 Epub Dec. 6.

Makino H, Malinow R. AMPA receptor incorporation into synapses during LTP: The role of lateral movement and exocytosis. Neuron. 2009; 64:381-390. [PubMed: 19914186]

Mameli M, Halbout B, Creton C, Engblom D, Parkitna JR, Spanagel R, Lüscher C. Cocaine-evoked synaptic plasticity: persistence in the VTA triggers adaptations in the NAc. Nat. Neurosci. 2009; 12:1036-1041. [PubMed: 19597494]

Mammen AL, Kameyama K, Roche KW, Huganir RL. Phosphorylation of the $\alpha$-amino-3-hydroxy-5methylisoxazole4-propionic acid receptor GluR1 subunit by calcium/calmodulin-dependent kinase II. J. Biol. Chem. 1997; 272:32528-32533. [PubMed: 9405465]

Man HY, Sekine-Aizawa Y, Huganir RL. Regulation of $\alpha$-amino-3-hydroxy-5-methyl-4isoxazolepropionic acid receptor trafficking through PKA phosphorylation of the Glu receptor 1 subunit. Proc. Natl. Acad. Sci. USA. 2007; 104:3579-3584. [PubMed: 17360685]

Mangiavacchi S, Wolf ME. D1 dopamine receptor stimulation increases the rate of AMPA receptor insertion onto the surface of cultured nucleus accumbens neurons through a pathway dependent on protein kinase A. J. Neurochem. 2004; 88:1261-1271. [PubMed: 15009682] 
McCutcheon JE, Wang X, Ford KA, Tseng KY, Wolf ME, Marinelli M. Calcium-permeable AMPA receptors are present in nucleus accumbens synapses after long withdrawal from cocaine selfadministration but not experimenter-administered cocaine. Soc. Neurosci. Abstr. 2010; 36 668.27.

O'Brien CP, Childress AR, McLellan AT, Ehrman R. Classical conditioning in drug-dependent humans. Ann. N. Y. Acad. Sci. 1992; 654:400-415. [PubMed: 1632593]

Oh MC, Derkach VA, Guire ES, Soderling TR. Extrasynaptic membrane trafficking regulated by GluR1 serine 845 phosphorylation primes AMPA receptors for long-term potentiation. J. Biol. Chem. 2006; 281:752-758. [PubMed: 16272153]

Opazo P, Labrecque S, Tigaret CM, Frouin A, Wiseman PW, de Koninck P, Choquet D. CaMKII triggers the diffusional trapping of surface AMPARs through phosphorylation of stargazin. Neuron. 2010; 67:239-252. [PubMed: 20670832]

Passafaro M, Piëch V, Sheng M. Subunit-specific temporal and spatial patterns of AMPA receptor exocytosis in hippocampal neurons. Nat. Neurosci. 2001; 4:917-926. [PubMed: 11528423]

Pierce RC, Kalivas PW. Repeated cocaine modifies the mechanism by which amphetamine releases dopamine. J. Neurosci. 1997; 17:3254-3261. [PubMed: 9096158]

Pierce RC, Quick EA, Reeder DC, Morgan ZR, Kalivas PW. Calcium-mediated second messengers modulate the expression of behavioral sensitization to cocaine. J. Pharm. Exp. Ther. 1998; 286:1171-1176.

Plant K, Pelkey KA, Bortolotto ZA, Morita D, Terashima A, McBain CJ, Collingridge GL, Isaac JT. Transient incorporation of native GluR2-lacking AMPA receptors during hippocampal long-term potentiation. Nat. Neurosci. 2006; 9:602-604. [PubMed: 16582904]

Reichel CM, Bevins RA. Forced abstinence model of relapse to study pharmacological treatments of substance use disorder. Curr. Drug Abuse Rev. 2009; 2:184-194. [PubMed: 19630748]

Reimers JM, Milovanovic M, Wolf ME. Quantitative analysis of AMPA receptor subunit composition in addiction-related brain regions. Brain Res. 2010 Epub Oct. 11.

Roche KW, O'Brien RJ, Mammen AL, Bernhardt J, Huganir RL. Characterization of multiple phosphorylation sites on the AMPA receptor GluR1 subunit. Neuron. 1996; 16:1179-1188. [PubMed: 8663994]

Schumann J, Yaka R. Prolonged withdrawal from repeated noncontingent cocaine exposure increases NMDA receptor expression and ERK activity in the nucleus accumbens. J. Neurosci. 2009; 29:6955-6963. [PubMed: 19474322]

Sharp AH, Black JL III, Dubel SJ, Sundarraj S, Shen J-P, Yunker AMR, Copeland TD, McEnery MW. Biochemical and anatomical evidence for specialized voltage-dependent calcium channel y isoform expression in the epileptic and ataxic mouse, stargazer. Neuroscience. 2001; 105:599-617. [PubMed: 11516827]

Shepherd JD, Huganir RL. The cell biology of synaptic plasticity: AMPA receptor trafficking. Annu. Rev. Cell Dev. Biol. 2007; 23:613-643. [PubMed: 17506699]

Shi Y, Lu W, Milstein AD, Nicoll RA. The stoichiometry of AMPA receptors and TARPs varies by neuronal cell type. Neuron. 2009; 62:633-640. [PubMed: 19524523]

Singer BF, Loweth JA, Neve RL, Vezina P. Transient viral-mediated overexpression of $\alpha$-calcium/ calmodulin-dependent protein kinase II in the nucleus accumbens shell leads to long-lasting functional upregulation of $\alpha$-amino-3-hydroxyl-5-methyl-4-isoxazole-propionate receptors: dopamine type-1 receptor and protein kinase A dependence. Eur. J. Neurosci. 2010; 31:12431251. [PubMed: 20345911]

Song J, Shen G, Greenfield LJ Jr, Tietz EI. Benzodiazepine withdrawal-induced glutamatergic plasticity involves up-regulation of GluR1-containing $\alpha$-amino-3-hydroxy-5-methylisoxazole-4propionic acid receptors in hippocampal CA1 neurons. J. Pharmacol. Exp. Ther. 2007; 322:569581. [PubMed: 17510319]

Sumioka A, Yan D, Tomita S. TARP phosphorylation regulates synaptic AMPA receptors through lipid bilayers. Neuron. 2010; 66:755-767. [PubMed: 20547132]

Sun X, Milovanovic M, Zhao Y, Wolf ME. Acute and chronic dopamine receptor stimulation modulates AMPA receptor trafficking in nucleus accumbens neurons co-cultured with prefrontal cortex neurons. J. Neurosci. 2008; 28:4216-4230. [PubMed: 18417701] 
Sun X, Wolf ME. Nucleus accumbens neurons exhibit synaptic scaling that is occluded by repeated dopamine pre-exposure. Eur. J. Neurosci. 2009; 30:539-550. [PubMed: 19674091]

Sun X, Zhao Y, Wolf ME. Dopamine receptor stimulation modulates AMPA receptor synaptic insertion in prefrontal cortex neurons. J. Neurosci. 2005; 25:7342-7351. [PubMed: 16093384]

Tomita S, Chen L, Kawasaki Y, Petralia RS, Wenthold RJ, Nicoll RA, Bredt DS. Functional studies and distribution define a family of transmembrane AMPA receptor regulatory proteins. J. Cell Biol. 2003; 161:805-816. [PubMed: 12771129]

Vanderschuren LJ, Everitt BJ. Drug seeking becomes compulsive after prolonged cocaine selfadministration. Science. 2004; 305:1017-1019. [PubMed: 15310907]

Wang L, Lv Z, Hu Z, Sheng J, Hui B, Sun J, Ma L. Chronic cocaine-induced H3 acetylation and transcriptional activation of CaMKII $\alpha$ in the nucleus accumbens is critical for motivation for drug reinforcement. Neuropsychopharmacology. 2010; 35:913-928. [PubMed: 20010550]

Wolf ME, Ferrario CR. AMPA receptor plasticity in the nucleus accumbens after repeated exposure to cocaine. Neurosci. Biobehav. Rev. 2010; 35:185-211. [PubMed: 20109488]

Wolf ME. The Bermuda Triangle of cocaine-induced neuroadaptations. Trends Neurosci. 2010a; 33:391-398. [PubMed: 20655604]

Wolf ME. Regulation of AMPA receptor trafficking in the nucleus accumbens by dopamine and cocaine. Neurotoxicol. Res. 2010b; 18:393-409.

Yang Y, Wang XB, Frerking M, Zhou Q. Delivery of AMPA receptors to perisynaptic sites precedes the full expression of long-term potentiation. Proc. Natl. Acad. Sci. USA. 2008; 105:1138811393. [PubMed: 18682558]

Yang Y, Wang X-B, Zhou Q. Perisynaptic GluR2-lacking AMPA receptors control the reversibility of synaptic and spines modifications. Proc. Natl. Acad. Sci. USA. 2010; 107:11999-12004. [PubMed: 20547835]

Yudowski GA, Puthenveedu MA, Leonoudakis D, Panicker S, Thorn KS, Beattie EC, von Zastrow M. Real-time imaging of discrete exocytic events mediating surface delivery of AMPA receptors. J. Neurosci. 2007; 27:11112-11121. [PubMed: 17928453]

Zhu JJ, Qin Y, Zhao M, Van Aelst L, Malinow R. Ras and Rap control AMPA receptor trafficking during synaptic plasticity. Cell. 2002; 110:443-455. [PubMed: 12202034]

Ziff EB. TARPs and the AMPA receptor trafficking paradox. Neuron. 2007; 53:627-633. [PubMed: 17329203] 

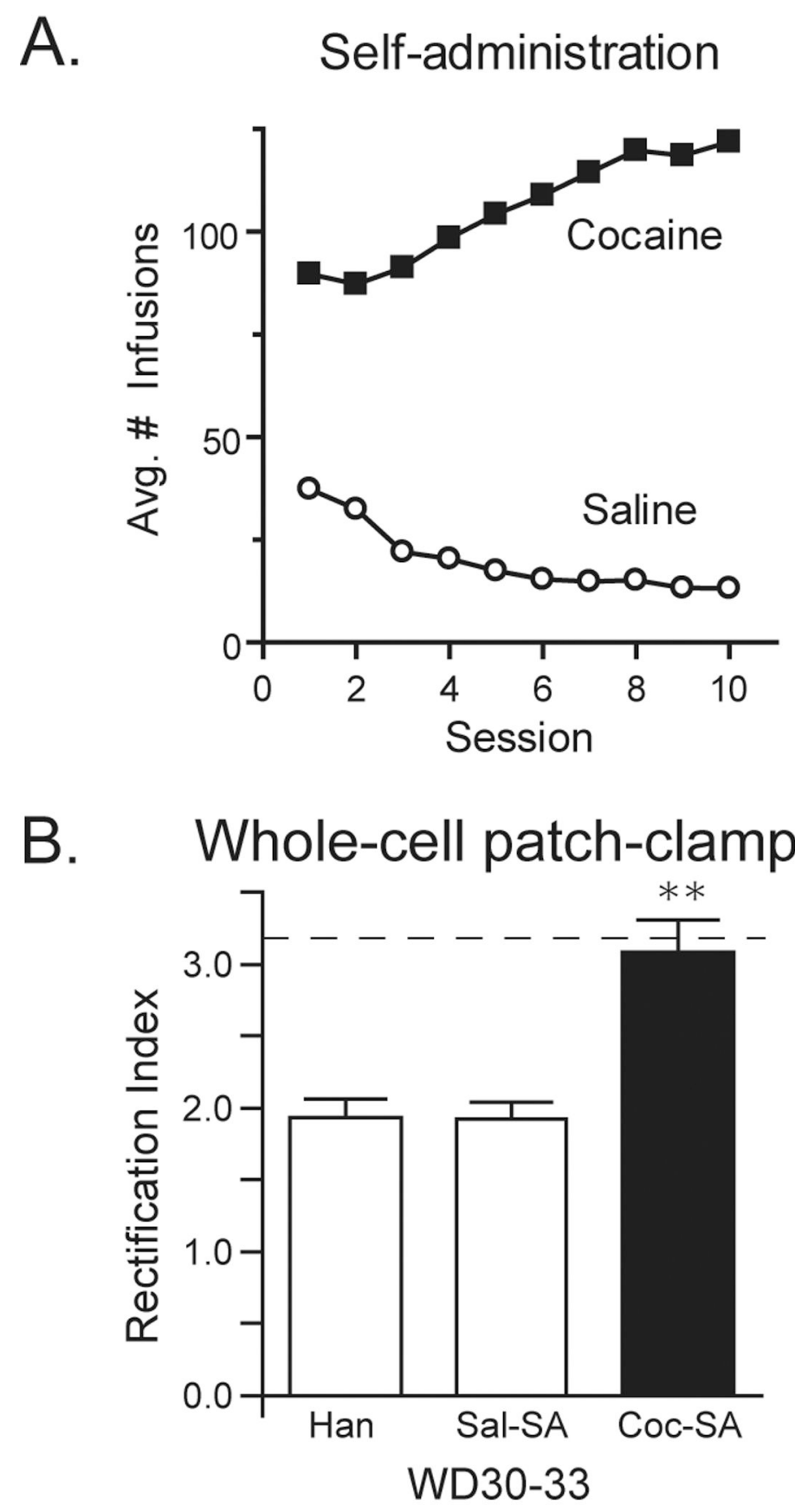

Figure 1.

Self-administration behavior and whole-cell patch-clamp recordings demonstrating presence of CP-AMPARs. A) Mean number of infusions ( \pm SEM) taken during each 6 hour selfadministration session for saline ( $\mathrm{N}=47$; open circles) and cocaine ( $\mathrm{N}=48$; closed squares) groups. All rats readily acquired cocaine self-administration and no significant differences in drug intake were found between the 4 cohorts studied. B) Rectification index (RI:

$\mathrm{EPSC}_{-70 \mathrm{mV}} / \mathrm{EPSC}_{+40 \mathrm{mV}}, \pm \mathrm{SEM}$ ) determined by whole-cell patch-clamp recordings of NAc medium spiny neurons 30-33 days after the last self-administration or handling session (WD30-33). No differences were found between handled (Han) and saline selfadministering groups (Sal-SA). Rats that previously self-administered cocaine had a 
significantly higher RI than both Han and Sal-SA controls, consistent with a greater synaptic content of CP-AMPARs. The dashed line represents the average RI for the Coc-SA WD42-47 group in our previous publication using the same self-administration regimen (Conrad et al., 2008). * p $<0.0001$. 
A. GluA1 PSD
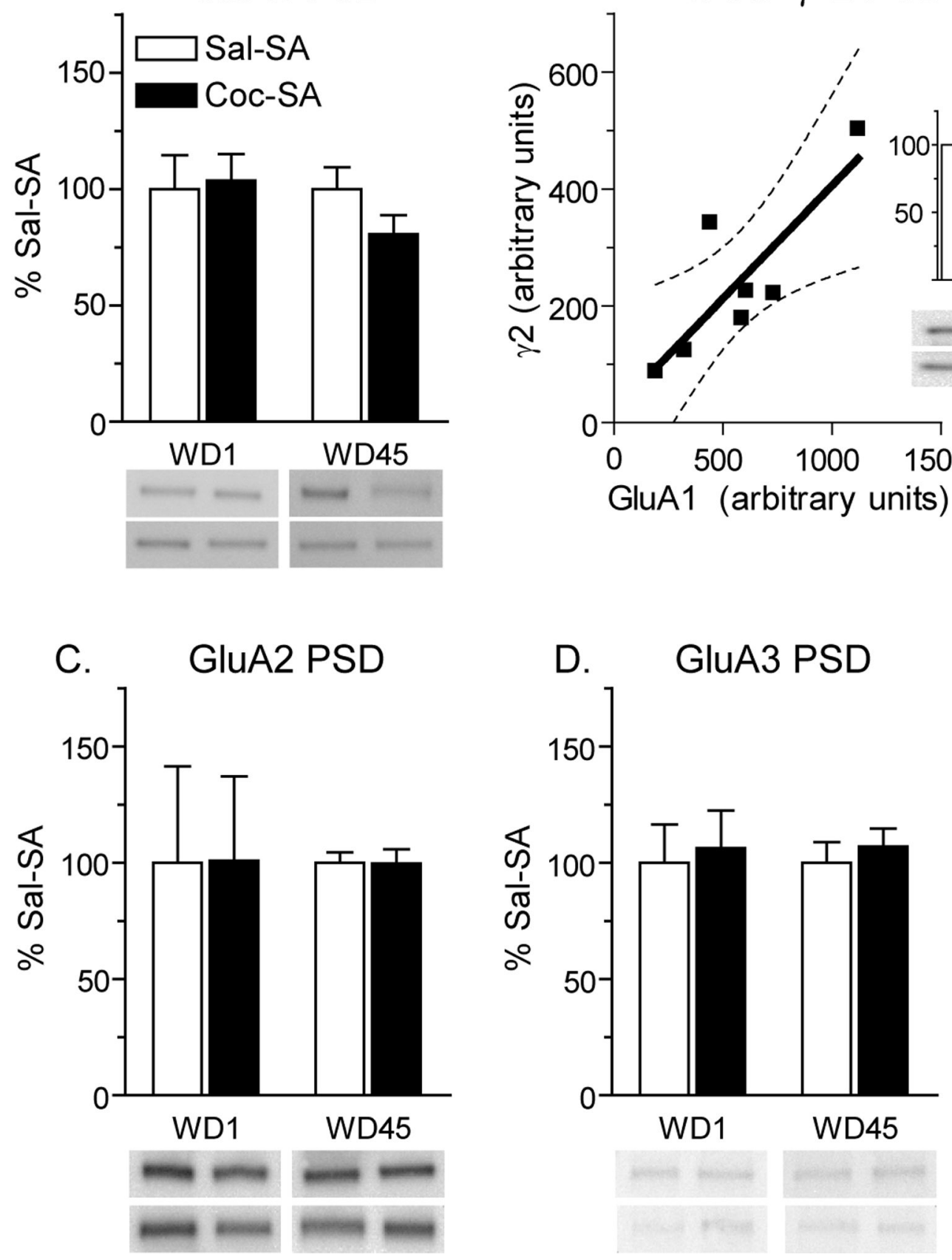

Figure 2.

Expression of AMPAR subunits and the TARP $\gamma 2$ in the NAc postsynaptic density (PSD) fraction after 1 or 45 days of withdrawal from self-administration. Data are presented as mean ( \pm SEM) expressed as percent of saline controls at each withdrawal time. A) GluA1 protein levels in the Coc-SA group were slightly decreased on WD45 compared to the SalSA WD45 group. B) Data suggesting that $\gamma 2$ and GluA1 are lost in parallel during preparation of PSD fractions from the Coc-SA WD45 group. Total $\gamma 2$ protein decreased slightly in the Coc-SA WD45 group (inset), similar to the decrease in GluA1 shown in panel $\mathrm{A}$, and levels of GluA1 protein and $\gamma 2$ protein were significantly correlated for individual rats in this group. The dashed lines show confidence interval and the solid line shows best 
fit. C, D) GluA2 and GluA3 protein levels were unchanged in the PSD fraction. In all panels, blot images from two rats in each group are shown by the two bands directly underneath each bar. For example, in panel A, the top four bands correspond (from left to right) to Sal-SA WD1, Coc-SA WD1, Sal-SA WD45 and Coc-SA WD45 rats. The lower four bands show another set of representative rats from each of these experimental groups. 
A.

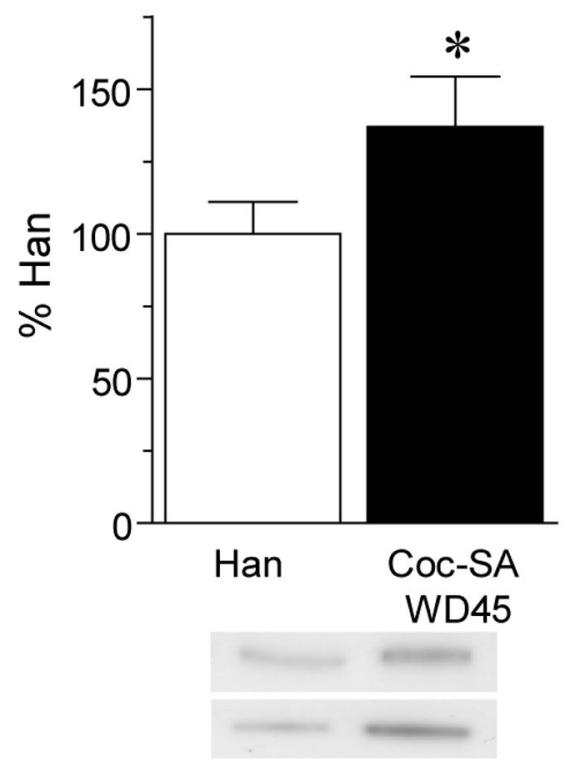

C.

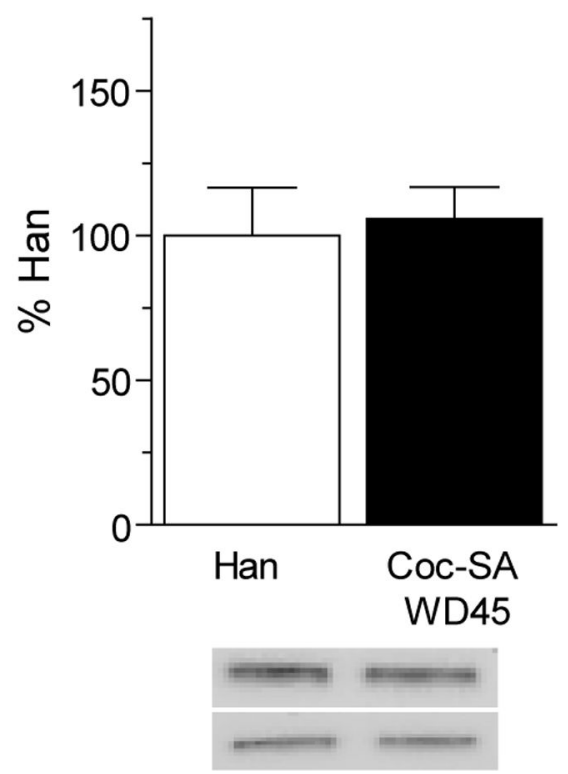

GluA2 LP1
B. TARPS LP1
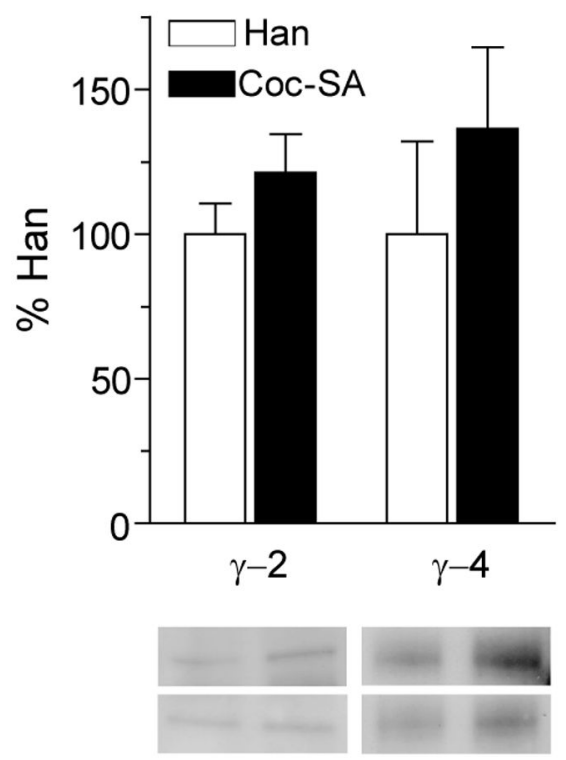

D. GluA3 LP1

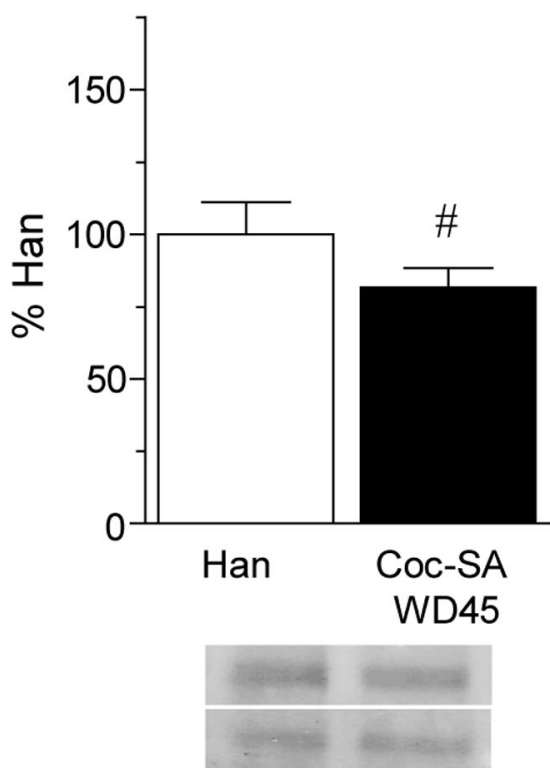

Figure 3.

Expression of AMPAR subunits and the TARPs $\gamma 2$ and $\gamma 4$ in the NAc lysed synaptosomal membrane (LP1) fraction after 45 days of withdrawal from cocaine-administration (Coc-SA WD45) or the last handling session (Han). Data are presented as mean ( \pm SEM) expressed as percent of handled controls. Importantly, Han and Sal-SA groups did not differ on several measures (see Results), including the RI (Fig. 1). A) GluA1 protein levels were significantly increased in the Coc-SA group compared to the Han group. B) Levels of $\gamma 2$ and $\gamma 4$ were slightly elevated. C) GluA2 protein levels were unchanged in the Coc-SA group. D) Levels of GluA3 protein were significantly decreased in the Coc-SA group compared to controls. Taken together, these data are consistent with an increase in CP-AMPARs in the Coc-SA 
WD45 group. In all panels, blot images from two rats in each group are shown by the two bands directly underneath each bar. For example, in panel A, the top two bands correspond (from left to right) to Han and Coc-SA WD45 rats. The lower two bands show another set of representative rats from each of these experimental groups. ${ }^{*} \mathrm{p}<.05, \# \mathrm{p}=.05$ 


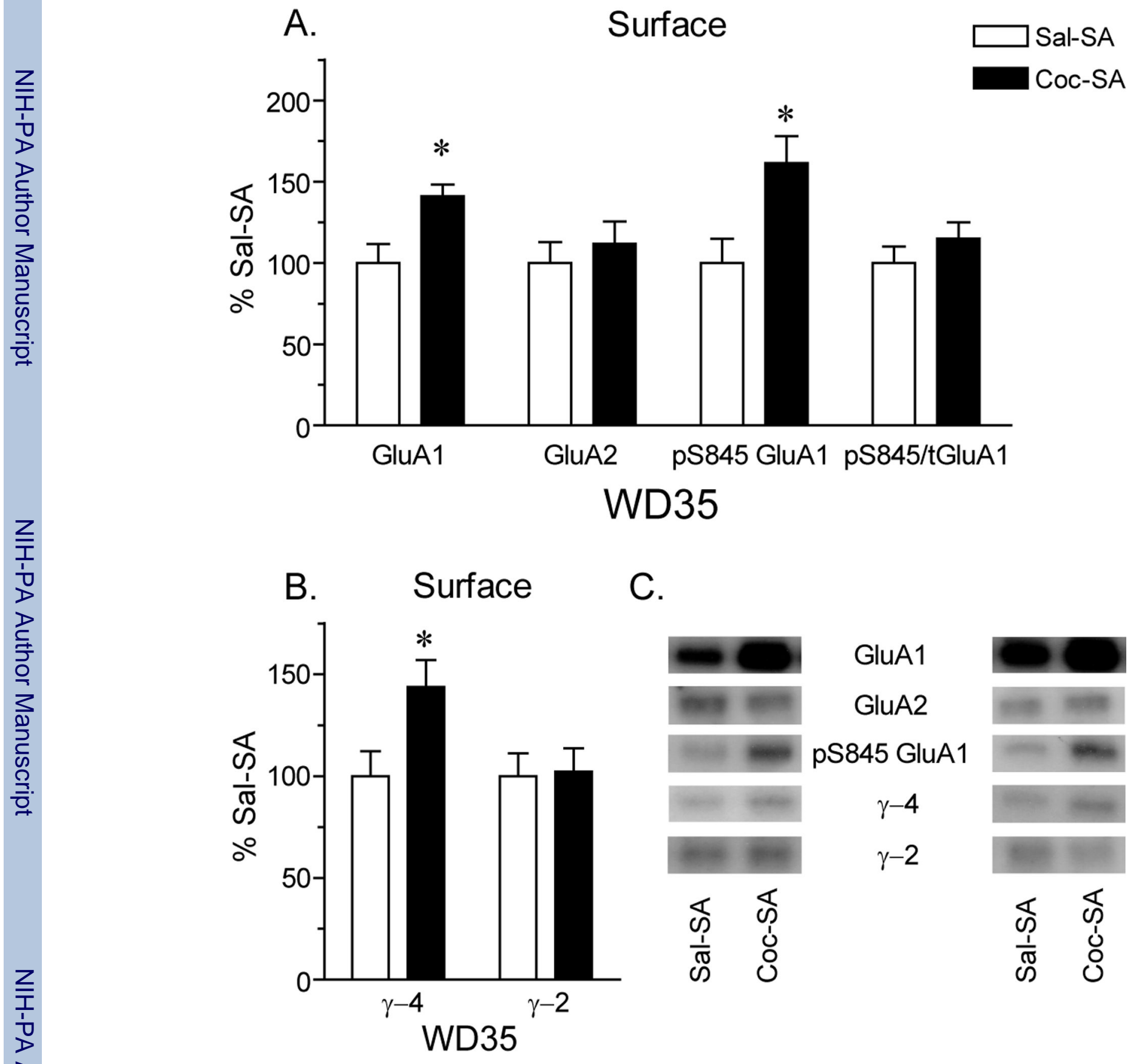

Figure 4.

Surface expression of AMPAR subunits and the TARPs $\gamma 2$ and $\gamma 4$ after 35 days of withdrawal from self-administration, determined using biotinylation. Data are presented as mean $( \pm$ SEM) expressed as percent of saline self-administering controls. A) Surface expression of GluA1 was significantly increased in the Coc-SA group compared to controls, whereas surface expression of GluA2 was unchanged. These data are consistent with insertion of CP-AMPARs, as also indicated by results in Fig. 1 (WD30-33) and in Fig. 3 (WD45). Surface expression of GluA1 phosphorylated at serine 845 (pS845 GluA1) was also significantly increased in the Coc-SA group compared to the control group, while the ratio of pS845 GluA1/total (t) GluA1 was unchanged due to proportional increases in both 
numerator and denominator. B) Surface expression of $\gamma 4$ was significantly increased in the Coc-SA group compared to the Sal-SA group, whereas $\gamma 2$ levels were unchanged. C) Representative blots for data graphed in panels A and B. Data from one pair of Sal-SA and Coc-SA rats are shown to the left of the labels, while another pair is shown to the right. Overall, the data indicate an increase in cell surface GluA1-containing AMPARs phosphorylated at S845 (see Discussion). *p<.05 


\section{Extrasynaptic Membranes}

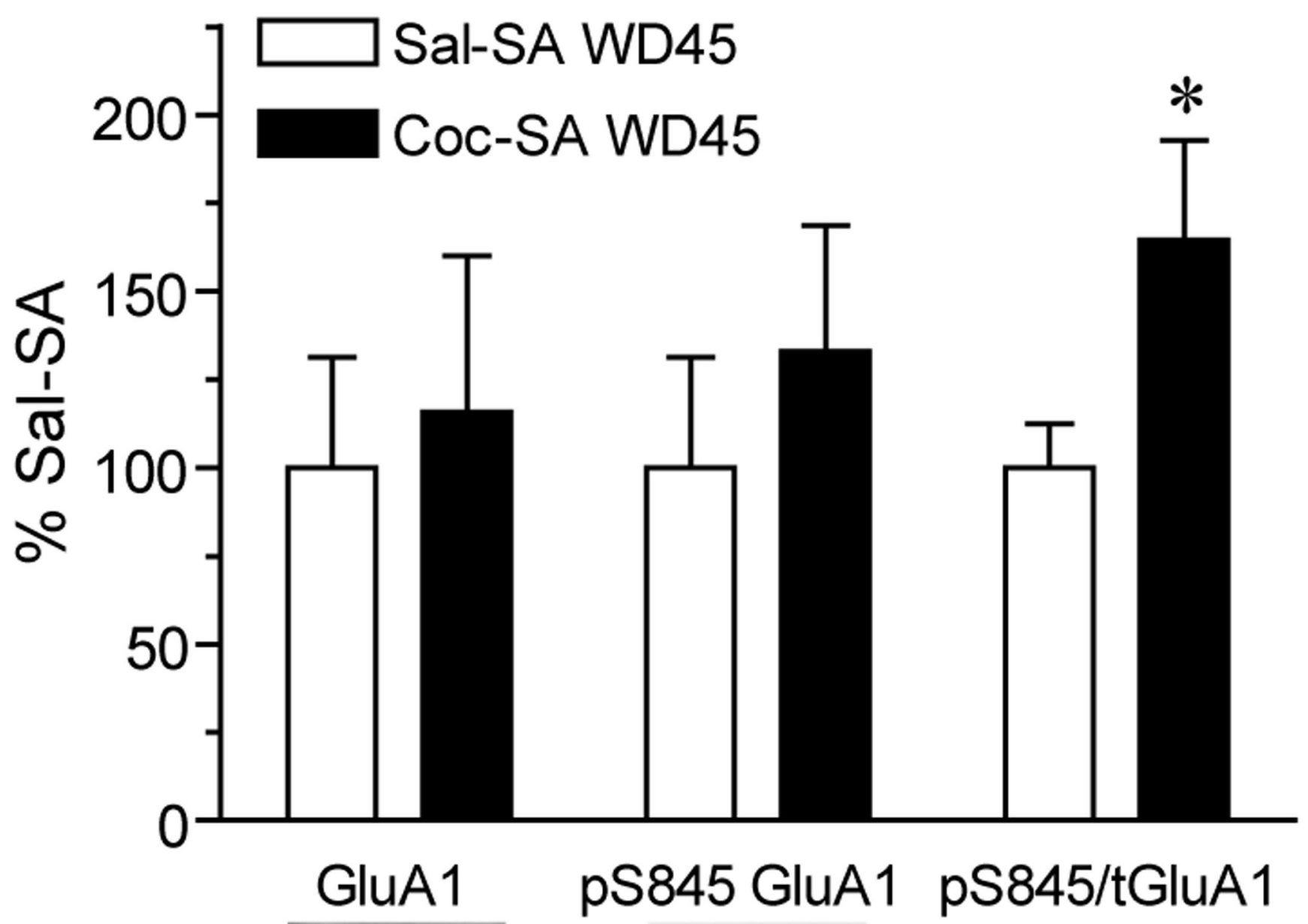

Figure 5.

Levels of total GluA1 and GluA1 phosphorylated on S845 (pS845 GluA1) in an extrasynaptic membrane-enriched fraction prepared after 45 days of withdrawal from selfadministration. Data are presented as mean $( \pm$ SEM) expressed as percent of saline selfadministering controls. The ratio of pS845 GluA1/total (t) GluA1 was significantly increased in the Coc-SA group compared to the Sal-SA group. Phosphorylation of GluA1containing AMPARs may promote their synaptic incorporation (see Discussion). Blot images from two rats in each group are shown by the two bands directly underneath each bar. Thus, the top two bands on the left correspond to GluA1 bands for Sal-SA and Coc-SA rats, while the two bands directly underneath show GluA1 bands from another pair of SalSA and Coc-SA rats. $* \mathrm{p}<.05$ 


\section{A. pCaMKIl $\alpha /$ tCaMKIl $\alpha$ PSD} ๙̊ำ

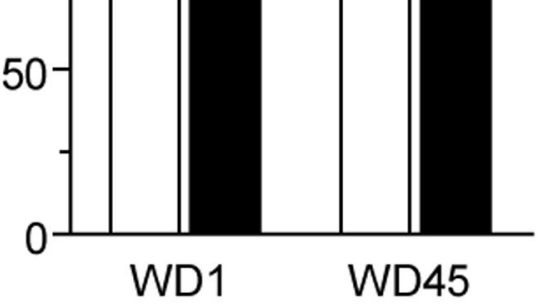

Figure 6. data graphed in panels A, B and C. *p<.05
B. pCaMKII $\beta / \mathrm{tCaMKII} \beta$ PSD

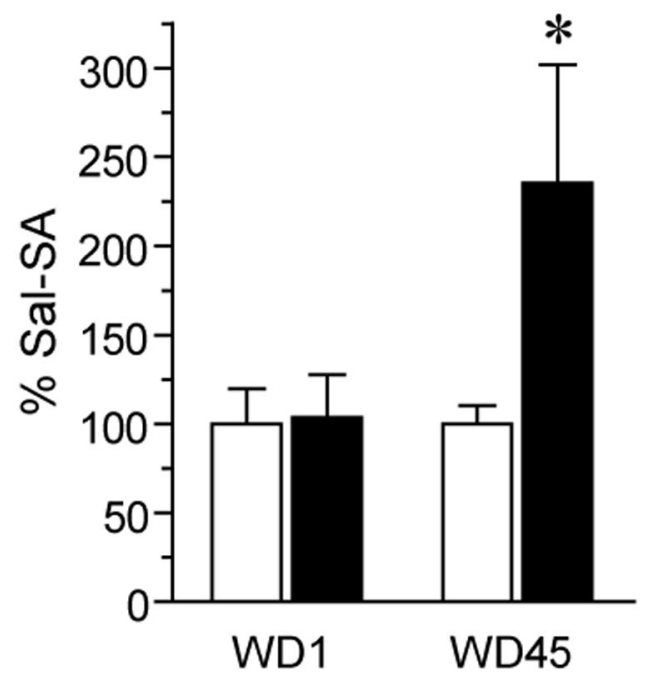

D.
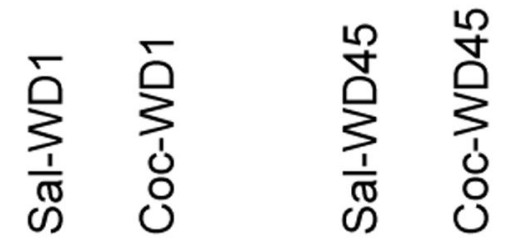

tCaMKII $\begin{aligned} & \alpha \\ & \beta\end{aligned}$

pCaMKII $\begin{gathered}\alpha \\ \beta\end{gathered}$

tCaMKI

pCaMKI
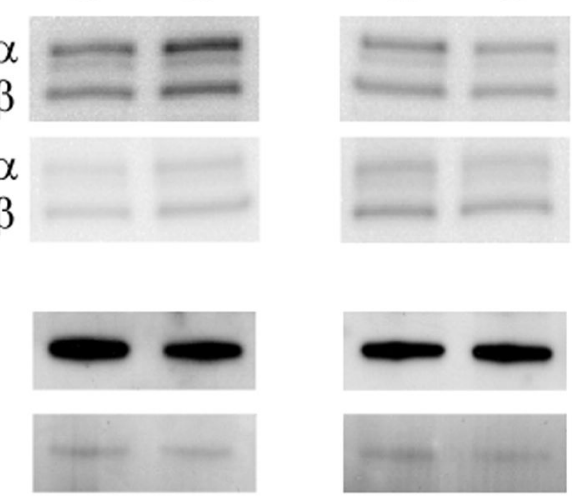

Phosphorylation state of CaMKII $\alpha / \beta$ and CaMKI in the PSD fraction after 1 or 45 days of withdrawal from self-administration. Data are presented as mean $( \pm$ SEM) expressed as percent of saline controls at each withdrawal time. A) The ratio of pCaMKII $\alpha(50 \mathrm{kD})$ to total (t) CaMKII $\alpha$ was significantly increased on WD45 in the Coc-SA group compared to the Sal-SA group. B) The ratio of pCaMKII $\beta(60 \mathrm{kD})$ to total CaMKII $\beta$ was also significantly increased on WD45 in the Coc-SA group. C) CaMKI and pCaMKI levels were unchanged after withdrawal from cocaine self-administration. D) Representative blots for 


\section{A. Total ERK1 and ERK2 PSD}

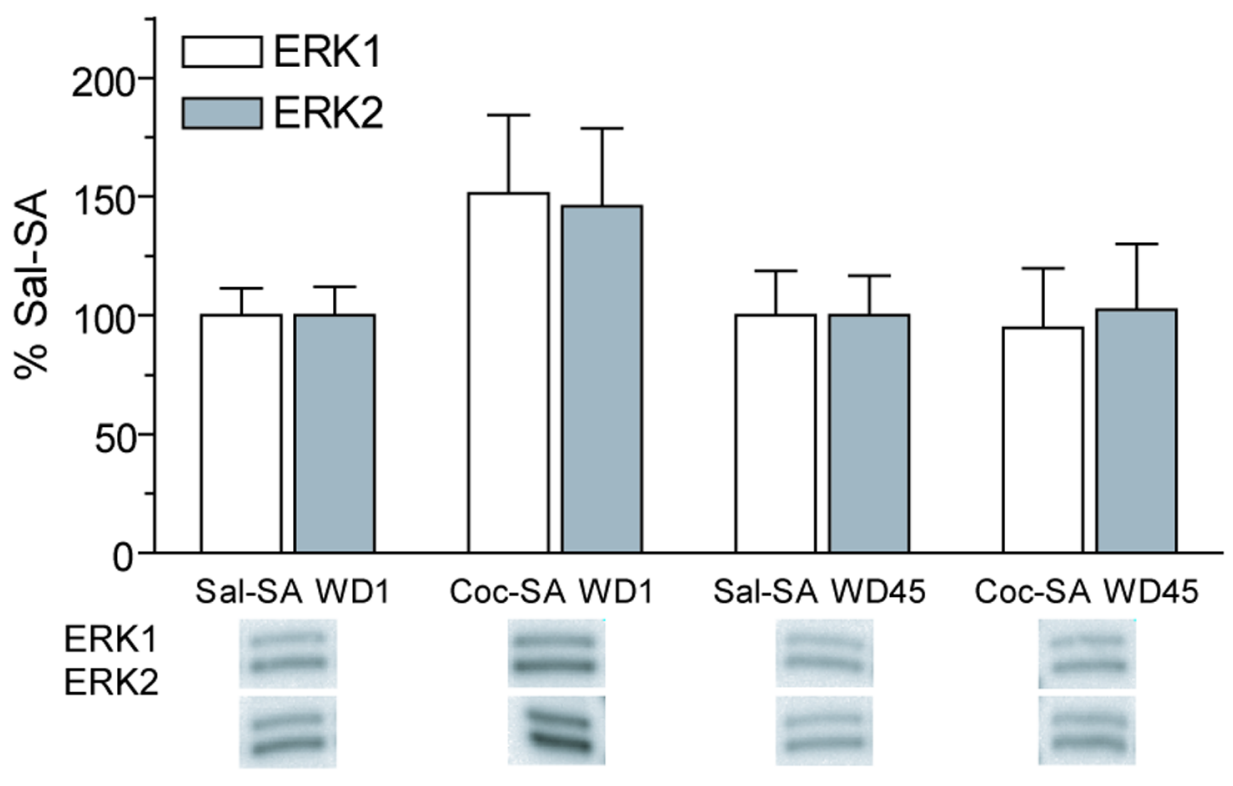

B. pERK2 PSD

C. pERK2/tERK2 PSD
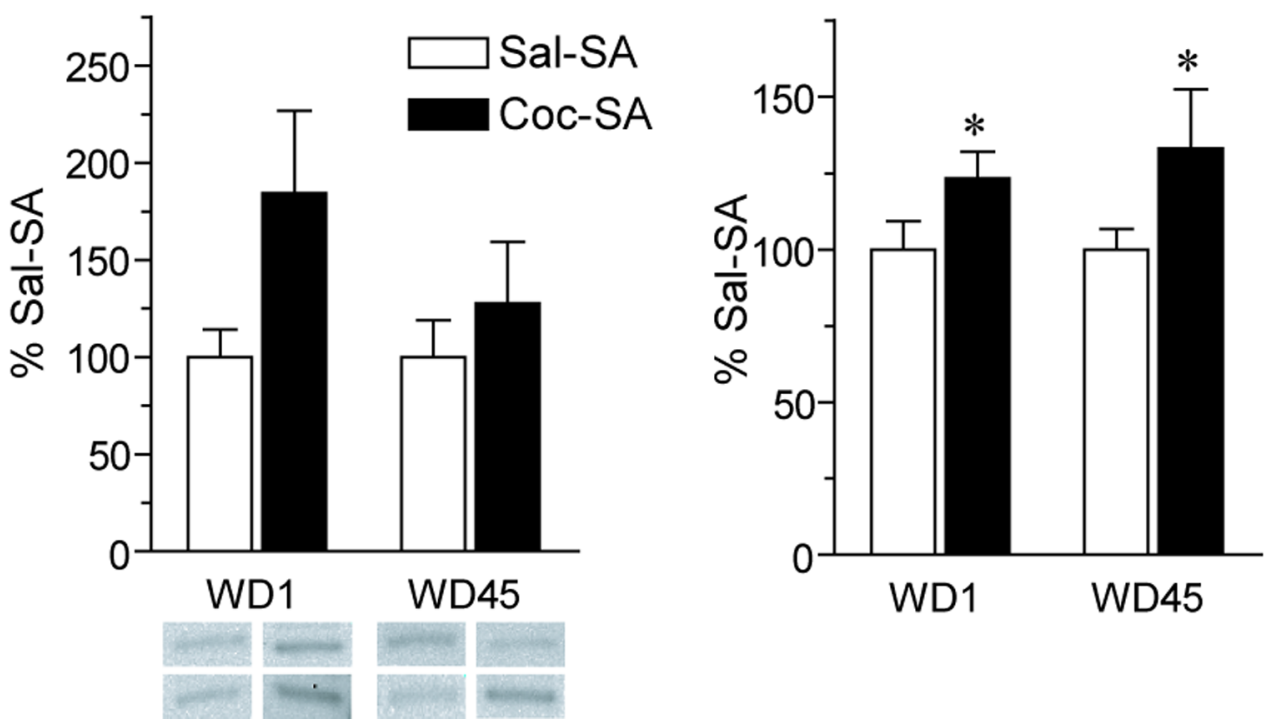

Figure 7.

Levels of ERK1 and ERK2 protein and ERK2 phosphorylation in the PSD fraction after 1 or 45 days of withdrawal from self-administration. Data are presented as mean ( \pm SEM) expressed as percent of saline controls at each withdrawal time. A) Total levels of ERK1 and ERK2 were slightly elevated on WD1 in the Coc-SA group; however, this did not reach statistical significance. B) Similar to results for total ERK in panel A, pERK2 levels were slightly elevated on WD1 in the Coc-SA group, but this was not statistically significant. On WD45, there was a small trend towards an increase in pERK2 levels in the Coc-SA group. C) The ratio of pERK2/total (t) ERK2 was significantly increased in the Coc-SA group compared to Sal-SA controls on both withdrawal days due to larger increases in pERK2 than 
total ERK2. While ratios appear similar for Coc-SA groups on WD1 and WD45 (panel C), note the larger magnitude of shifts in total ERK2 (panel A) and pERK2 (panel B) on WD1. Levels of pERK1 in the PSD fraction were too low for reliable quantification.

Representative blots are shown for two rats in each experimental group. In panel A, the top blot shows ERK1 and ERK2 bands for one rat from the experimental group above the blot, and the bottom blot shows ERK1 and ERK2 bands for another rat in this group. In panel B, the top four bands correspond (left to right) to Sal-SA WD1, Coc-SA WD1, Sal-SA WD45 and Coc-SA WD45 rats, while the lower four bands show another set of representative rats from each of these experimental groups. ${ }^{*} \mathrm{p}<.05$ 